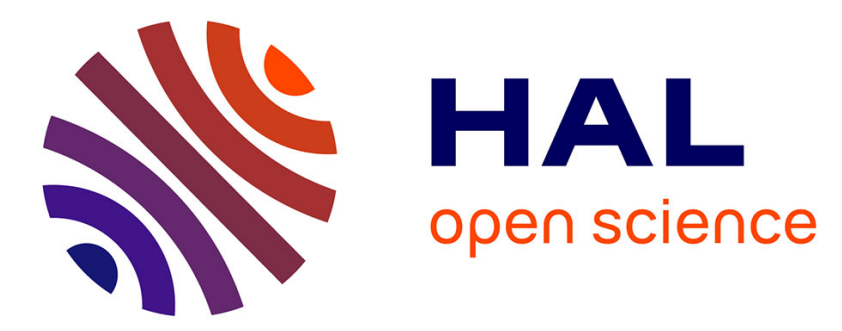

\title{
Fully Coupled CFD Simulation of the Ignition Risk of Unburnt Gases in an Exhaust System Connected to a Mechanically Ventilated Enclosure Fire
}

H. Q. Dong, B. Magnognou, J.-P. Garo, B. Coudour, Hui-Ying Wang

\section{- To cite this version:}

H. Q. Dong, B. Magnognou, J.-P. Garo, B. Coudour, Hui-Ying Wang. Fully Coupled CFD Simulation of the Ignition Risk of Unburnt Gases in an Exhaust System Connected to a Mechanically Ventilated Enclosure Fire. Fire Technology, 2019, 55 (1), pp.149-174. 10.1007/s10694-018-0781-4 . hal-02353242

\author{
HAL Id: hal-02353242 \\ https://hal.science/hal-02353242
}

Submitted on 23 Nov 2020

HAL is a multi-disciplinary open access archive for the deposit and dissemination of scientific research documents, whether they are published or not. The documents may come from teaching and research institutions in France or abroad, or from public or private research centers.
L'archive ouverte pluridisciplinaire HAL, est destinée au dépôt et à la diffusion de documents scientifiques de niveau recherche, publiés ou non, émanant des établissements d'enseignement et de recherche français ou étrangers, des laboratoires publics ou privés. 


\title{
Fully coupled CFD simulation of the ignition risk of unburnt gases in an exhaust system connected to a mechanically ventilated enclosure fire
}

\author{
H. Q. Dong, B. Magnognou, J.P. Garo, B. Coudour and Hui-Ying Wang \\ wang@ensma.fr \\ Fax : 33549498291 \\ Institut P', Fluides-Thermique-Combustion, CNRS, ENSMA, Université de Poitiers, \\ BP 40109 \\ F86961 Futuroscope Chasseneuil Cedex, France
}

\begin{abstract}
Predictive simulations of liquid pool fires are based on the previous experimental study from a reduced mechanically ventilated enclosure with a length/height and width of $2 \mathrm{~m}$. An external ventilation system provides an air supply rate ranging from 24 to $40 \mathrm{~m}^{3} / \mathrm{h}$, corresponding to 3 and 5 Air Change Per Hour (ACPH), respectively. A circular heptane or dodecane pan with a diameter varying from 23 to $40 \mathrm{~cm}$ is placed in the middle of the enclosure. The proposed liquid evaporation model in combustion environments is fully coupled with CFD simulation. The results show that the fuel pan above $30 \mathrm{~cm}$ leads to faster fire growth implying more important peak up to $200 \mathrm{~kW}$ in heat release rate and thus more dangerous fire. In the early stages of a fire, a stratified hotter unburnt fuels layer with a concentration beyond the Lower Flammability Limit (LFL) is formed in the extraction duct connected to a mechanically ventilated enclosure fire. With a long time delay (about $21 \mathrm{~min}$ in the current study), the energy released per mass of oxygen consumed allows to raise the smoke temperature above $350^{\circ} \mathrm{C}$. Occurrence of flame extinction in vitiated air enclosure with an oxygen concentration below 5\% makes a sudden decrease of the pressure level inside enclosure due to cooling effects. This induces a sudden supply of fresh air from dilution duct, providing a sufficient oxygen concentration with a molar fraction of about $10 \%$ for triggering the ignition of a hotter fuel-air mixture near the extraction duct. Such auto-ignition, determined experimentally by visual identification of fire, is likely a random phenomenon with a probability of $50 \%$ due to the heat leakage through the walls of the experimental facility. When the compartment is more heat-tight by using an insulating material, the auto-ignition occurs for each fire tests. Globally, the phenomena with ignition near the extraction duct can be identified by a rapid decrease of unburnt fuel concentration towards a stoichiometric fuel-air mixture and a sharp increase of temperature with a peak reaching a typical flame temperature of $550^{\circ} \mathrm{C}$ there.
\end{abstract}

Keywords: enclosure fire, liquid fuel, ventilation rate, ignition risk, extraction duct, dilution duct

\section{Introduction}

Liquid pool fires are a significant hazard to industrial facilities. The liquids could originate e.g. from leaking transformers generators or other machinery. Knowing the fire burning rate is the starting point of any fire safety analysis. The factors affecting the burning rates of liquid pool fires in open atmosphere are well known for a wide variety of liquids. The empirical correlation of Peatross [1] for fuel mass loss rate of a liquid fuel is limited to the large enclosure where the heat fluxes from hot wall can be negligible. The theoretical model developed by Utiskul [2] allows to predict mass loss rate solely for small-scale pool fire experiments, since flame radiation heat feedback to the liquid surface was neglected. The study of Tewarson [3] was focused on a steady-state heat balance at the condensed fuel surface with a radiation adjustment through the Spalding number. The work of Orloff [4] illustrated the application of Froude 
modelling to the development of a homogeneous fire radiation correlation. Based on the measured radiative heat feedback, the work of Hamins [5] developed a global approach to predict the mass burning flux for liquid pool fires. In the analytical correlation of Beaulieu [6], the measured flame temperature is required to quantify the effect of enhanced ambient oxygen concentration on flame heat flux.

However, many liquid pool fire scenarios involve fires in confined spaces [7-11]. This problematic is especially encountered in the highly confined nuclear facilities equipped with forced interconnecting ventilation system [12] in order to contain the potential release of radioactive material and avoid dispersion to the outside environment. The situation is even more complex if ventilation is mechanically controlled, and the burning rate can be significantly different from the ones measured in open atmosphere [13]. These differences are mainly caused by air ventilation and heat radiation from hot walls and the hot gas layer. Relatively few attempts have been made of predicting rather than prescribing the burning rates in compartments [14, 15]. An empirical treatment of soot formation in the work of Nasr [15] has a profound influence on the radiation emission with regard to the heat feedback, and consequently, to the burning rate. The liquid pool fire problematic in a confined environment can be separated in several individual processes: during the initial phase, the fire growths as long as it is fuel-controlled; the fire can become limited by the available oxygen with generation of unburnt fuel gases; the fire enters the exhaust phase in a progressively vitiated air enclosure. In a typical ignition scenario, the atmosphere in the extraction duct consists of large uncombusted gases with a concentration generally above the lower flammability limit at elevated temperature. The experimental study of Lassus [16, 17] showed that in a highly confined setting with interconnecting ventilation ducts, an extraction duct is an important pathway for the onset of ignition of a flammable mixture of pyrolysis gases and vitiated air with presence of a dilution duct.

Ignition risk is an important concept, especially for establishing evaluation methodologies of a scenario regarding its hazard and adverse impact for fire safety applications. Despite the mechanisms involved in ignition are well known [18], a rigorous definition of situations leading to ignition inside an extraction duct is still vague. This phenomenon generally occurs in conditions where a compartment containing a fire has a very limited fresh air supply, and the fire is considerably ventilation-controlled or extinguished. The aim of this research is to discover if there are critical conditions leading to ignition inside an extraction duct by combining theory and experiment for different fuels and ventilation rates. Quantitative comparisons are made between several computational results and measurements from a liquid pool fire scenario in a confined facility $[16,17]$.

\section{Experimental set-up}

The experimental facility and its geometry are shown in Figure 1(a, b, c). The reduced-scale enclosure with a length/height and width of $2 \mathrm{~m}$ is equipped with an external ventilation system consisting of two intake ducts and an extraction duct. Ducts have a square section of $0.2 \times 0.2$ $\mathrm{m}^{2}$. The intake is placed closer to the floor at a height of $0.3 \mathrm{~m}$ and the exhaust is placed near the ceiling at a height of $1.7 \mathrm{~m}$. Walls of the enclosure are made of concrete with a thermal conductivity of $1 \mathrm{~W} / \mathrm{m} . \mathrm{K}$, a density of $2100 \mathrm{~kg} / \mathrm{m}^{3}$, a specific heat of $0.88 \mathrm{~kJ} / \mathrm{kg} . \mathrm{K}$, and a thickness of $0.2 \mathrm{~m}$. The stainless-steel circular pan containing heptane or dodecane with a diameter D varying from 23 to $40 \mathrm{~cm}$ is placed in the middle of the enclosure, slightly elevated at a height of $0.3 \mathrm{~m}$. Measurements performed include the fuel mass loss rate, fire duration, temperature and chemical species concentrations of gases filling the enclosure. As shown in 
Fig.1(b, c), the gas temperature in the enclosure is analysed from seven vertical profiles near the fire source and at the extraction/dilution ducts. Each of the seven profiles comprises eight thermocouples positioned at regular intervals over the height of the enclosure. The temperature measurements in the compartment were performed with chromel-alumel thermocouples (type $\mathrm{K}$ ) of a $0.5 \mathrm{~mm}$ wire. The response time of the thermocouples used in our experiment is close to a second by including thermal mass inertia and accumulation of soot particles. Thus, accurate measurement of flame temperature by using the thermocouples is quite difficult due to a multitude of potential errors, including surface reactions, radiation, stem loss, etc. Concentrations of the chemical species, such as $\mathrm{O}_{2}, \mathrm{CO}, \mathrm{CO}_{2}, \mathrm{H}_{2}$ and primary fuel were measured by using a sampling probe connected to a chemical analyser.

Since experiments in full scale are expensive, the numbers of tests are limited. With reducedscale enclosure, more tests may be carried out but the scale reduction must respect several scaling laws adapted to the studied problem. Fire compartment tests have been conducted at a reduced geometric scale, maintaining a constant Froude number, $\mathrm{Fr}=\mathrm{u}^{2} / \mathrm{gL}$ where $\mathrm{L}$ and $\mathrm{u}$ denote the characteristic length and velocity, respectively. Reynolds number is large enough to ensure the turbulence of the flow. The Froude number is then made constant by $\mathrm{u} \propto \mathrm{L}^{1 / 2}$ that comes from dimensionless variable of momentum conservation. Flow time scale is obtained from mass conservation by $\tau \propto \frac{\mathrm{L}}{\mathrm{u}} \propto \mathrm{L}^{1 / 2}$. Since the ventilation flow rate is the inverse of $\tau$, it scales with $\mathrm{L}^{-1 / 2}$. From dimensionless variable of the energy equation, the source term contains the Zukoski number [19], defined as $\frac{\dot{\mathrm{Q}}}{\mathrm{Fr}_{\mathrm{L}}^{5 / 2}\left(\rho \mathrm{C}_{\mathrm{p}} \mathrm{T}\right) \mathrm{g}^{1 / 2}}$. Based on such analysis, the experimental results from a reduced scale enclosure can be extended to a full scale one by imposing a preservation of the ratio $\left(\dot{\mathrm{Q}}^{2} / \mathrm{L}^{5}\right)$ between heat release rate $(\dot{\mathrm{Q}})$ and characteristic length $(\mathrm{L})$. Moreover, in order to obtain a good similitude between a full scale and a reduced scale compartments, radiative heat flux from wall must not have an influence on heat release rate (HRR). Thus, the experimental fire power in the reduced scale enclosure with a volume of $8 \mathrm{~m}^{3}$ should be lower than $130 \mathrm{~kW}$. Such reduced scale enclosure corresponds to a full scale one with a volume of approximately $100 \mathrm{~m}^{3}$ and a HRR of $1 \mathrm{MW}$ [12].

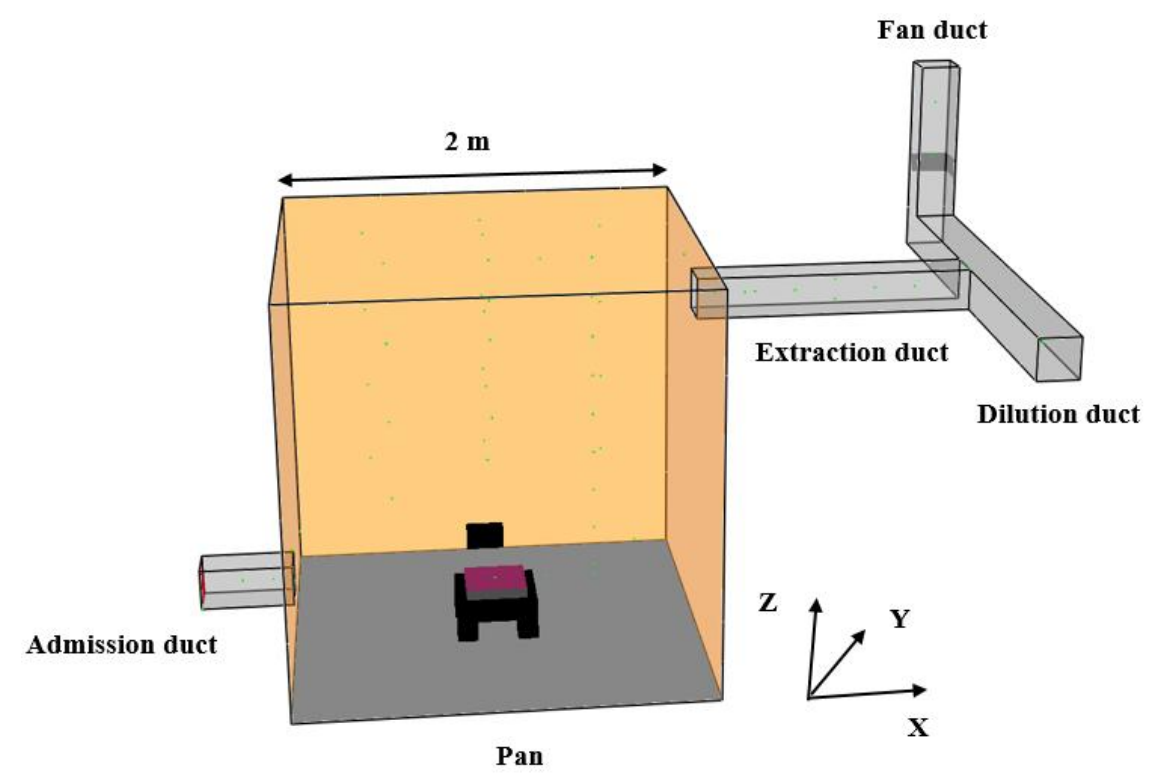

1a) $3 \mathrm{D}$ view of the computational domain and coordinate system 


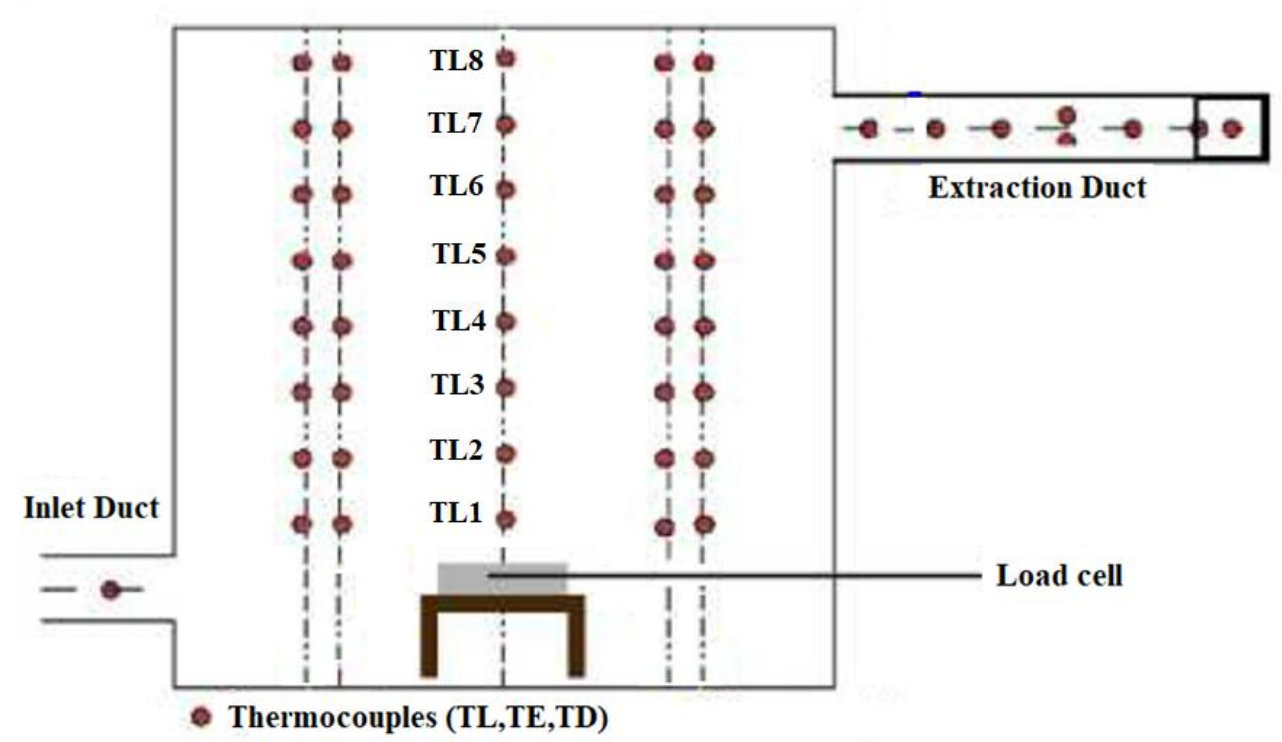

1b) Measurement positions from the side ( $\mathrm{x}, \mathrm{z})$ view

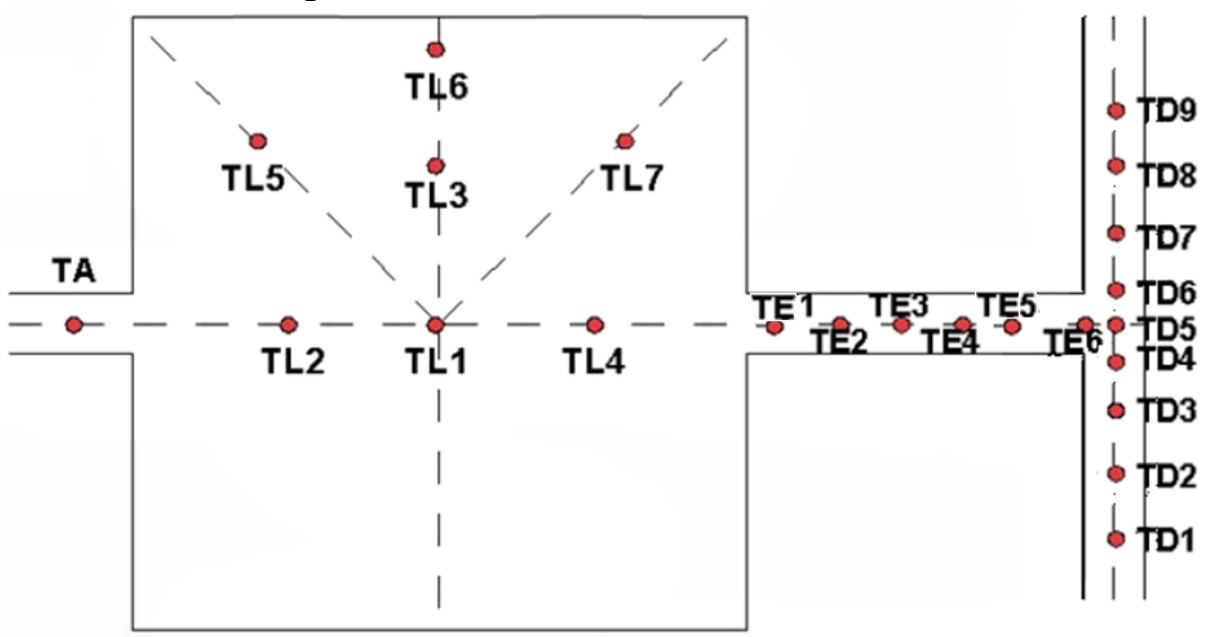

- Thermocoupes (TL,TE,TD)

1c) Measurement positions from the top ( $\mathrm{x}, \mathrm{y})$ view

Figure 1 . Scheme of the mechanically ventilated enclosure fire with a connection to an exhaust system

\section{Theoretical analysis}

Figure 1a) is a picture of $3 \mathrm{D}$ view of the computational domain which consists of four rectangular meshes connected to an enclosure. The coordinate system and the reduced scale enclosure geometry are also shown in Figure 1a). Advanced fire physics model, which is the subject of the current work, requires state-of-the-art submodels (combustion, multidimensional participating radiation, soot formation, heat transfer, liquid fuel vaporization, etc.) which are coupled with the flowfield governing momentum solution. The basis of the analysis is the conservation equations of mass, momentum, energy and species, a set of three-dimensional elliptic, time-dependent Navier-Stokes equations. Turbulence is modelled using a Smagorinsky sub-grid scale model in a Large Eddy Simulation. The precise formulation of the differential equations describing the model and the numerical technique can be found in FDS user guide [20].

Note that in the version 5 or 6 of FDS [20], the Stefan problem model is used for the liquid evaporation rate, which involved only mass transfer, since it was assumed that the liquid surface 
temperature was a known parameter. Moreover, the empirical parameter as soot yield is used for soot formation, which is well known for well-ventilated fires (for example, 0.042 for dodecane and 0.037 for heptane), but cannot be applied to under-ventilated enclosure fires. For a heavily sooting heptane or dodecane fire, the radiation feedback from the hot gas layer to the liquid-vapour interface is significantly affected by the soot production. In the current work, the proposed liquid evaporation model and soot one vary in complexity. In order to properly calculate the evaporation rate of liquid fuel, a classic principle of smoke point for soot formation and the liquid evaporation model in combustion environments were implemented in FDS5 for performing this study. Currently, implementation of the same soot and liquid evaporation models in FDS6 is in progress, and this will be the subject of future study and publications.

\subsection{Evaporation rate of liquid fuel}

For a liquid fuel, if the concentration of fuel gas in the flowing gas is less than the concentration of fuel at the liquid-vapor interface, a driving force for mass transfer exists and species fuel will diffuse from the liquid-gas interface to the freestream flow. In combustion environments, the freestream gas temperature, $\mathrm{T}_{\mathrm{g}}$, is much greater than the liquid boiling point, the surface temperature, $T_{s}$, is nearly equal to but slightly less than the liquid boiling point. Physically, heat from the flame to the liquid surface supplies the energy necessary to vaporize the liquid fuel, and the fuel vapor then diffuses from the liquid surface into the freestream reacting flow. Moreover, for a mechanically ventilated enclosure fire, the ventilation flow over the liquid surface steepens concentration and temperature gradients, and hence, increases mass- and heattransfer rates at the liquid surface, implying that convection enhances liquid vaporization rate. The film theory approach is used to incorporate convection in the liquid surface in keeping with our desire for simplicity. Mathematically, the overall conservations of mass and energy for this system can be integrated for determining the mass flux of liquid fuel [21], as follows,

$\dot{\mathrm{m}}_{\mathrm{F}}^{\prime \prime}=\frac{\rho \mathrm{D}}{\delta} \mathrm{Nu} \ln (\mathrm{B}+1)$

where $\rho$ is the gas density, D the mass diffusivity and $\delta$ the convective length scale. Physically, the Nusselt number, $\mathrm{Nu}$, is the dimensionless temperature gradient at the liquid surface, and the following correlation is recommended to evaluate it.

$\mathrm{Nu}=m \operatorname{Pr}^{1 / 3} \operatorname{Re}^{\mathrm{n}}$

Where Pr is Prandtl number, and $\mathrm{Re}=\frac{\rho \mathrm{u} \delta}{\mu}$ denotes the local Reynolds number calculated from the local velocity $\mathrm{u}$ and viscosity $\mu$. The empirical constants are given [21] as $\mathrm{m}=0.037$ and $n=4 / 5$ for the Reynolds number beyond $3 \times 10^{5}$, and $m=0.664$ and $n=1 / 2$ for Re below that value. The $\mathrm{B}$ denotes the mass transfer number, it is defined as,

$\mathrm{B}=\frac{\mathrm{H}_{\mathrm{c}} \nu_{\mathrm{F} / \mathrm{o}} \mathrm{Y}_{\mathrm{O} 2}+\mathrm{C}_{\mathrm{p}}\left(\mathrm{T}_{\mathrm{g}}-\mathrm{T}_{\mathrm{s}}\right)}{\mathrm{L}_{\mathrm{v}}+\mathrm{C}_{\mathrm{pl}}\left(\mathrm{T}_{\mathrm{s}}-\mathrm{T}_{0}\right)}$

where $V_{F / O}$ is the stoichiometric fuel/oxygen ratio, $\mathrm{H}_{\mathrm{c}}$ the heat of combustion, $\mathrm{C}_{\mathrm{pl}}$ the liquid specific heat, $C_{p}$ the gas specific heat, $L_{v}$ the fuel latent heat, and $T_{0}$ the liquid initial temperature. The liquid evaporation rate via the number $\mathrm{B}$ depends on the local oxygen concentration, $\mathrm{Y}_{\mathrm{O} 2}$, in a progressively vitiated air enclosure. The convective length scale $\delta$, in Eq.(1) is attached to the mesh size of the computational nodes immediately adjacent to a liquid surface. The Reynolds (Re) and the mass transfer (B) numbers are also dependent on the same mesh size via the thermo-physical properties, the oxygen mass fraction and the temperature in 
the flowing gas. Much more detailed information about the thermo-physical and combustion properties of the liquid fuel is provided in Table 1 for heptane and dodecane [20,21].

Table 1. Temperature-independent, thermo-physical and combustion properties of the liquid fuels as heptane and dodecane

\begin{tabular}{|l|l|l|}
\hline Property & Heptane & Dodecane \\
\hline Conductivity $(\mathrm{W} / \mathrm{m} \cdot \mathrm{K})$ & 0.17 & 0.14 \\
Heat capacity $(\mathrm{kJ} / \mathrm{kg} \cdot \mathrm{K})$ & 684 & 750 \\
Pyrolysis heat, $\mathrm{L}_{\mathrm{v}}(\mathrm{kJ} / \mathrm{kg})$ & 321 & 2.21 \\
Combustion heat, $\mathrm{H}_{\mathrm{c}}(\mathrm{kJ} / \mathrm{kg})$ & 44500 & 256 \\
Boiling temperature $\left({ }^{\circ} \mathrm{C}\right)$ & 98 & 44147 \\
\hline
\end{tabular}

Energy is conserved at the liquid-vapor interface. Heat is transferred from the gas to the liquid surface. Some of this energy goes into heating the liquid, while the remainder causes the phase change, as,

$\dot{\mathrm{q}}_{\text {pyro }}^{\prime \prime}=\dot{\mathrm{m}}_{\mathrm{F}}^{\prime \prime} \mathrm{Lv}$

This equation can be used to calculate the net heat transferred to the interface if the evaporation rate is known. The liquid fuel is assumed to be thermally-thick, a one-dimensional heat conduction equation for the material temperature is solved. The surface temperature, $T_{\mathrm{s}}$, of an evaporating liquid is affected by gains and losses of the heat at the interface :

$-\lambda \frac{\mathrm{d}_{\mathrm{T}}}{\mathrm{dn}}=\dot{\mathrm{q}}_{\mathrm{conv}}^{\prime \prime}+\dot{\mathrm{q}}_{\mathrm{rad}}^{\prime \prime}-\dot{\mathrm{q}}_{\mathrm{pyro}}$

Here, $\lambda$ is the thermal conductivity of condensed fuel. The Couette flow is assumed to prevail near the wall surface, and the convective heat feedback $\dot{q}_{\text {conv }}^{\prime \prime}$, is calculated from a wall function [22] far away from the wall for viscous effects to be negligible.

$\dot{\mathrm{q}}_{\text {conv }}=\frac{\left(\mathrm{T}_{\mathrm{g}}-\mathrm{T}_{\mathrm{s}}\right) \rho \mathrm{C}_{\mathrm{p}} \mathrm{C}_{\mu}^{1 / 4} \mathrm{k}^{1 / 2}}{\operatorname{Pr}\left[\frac{1}{\kappa} \ln \left(\mathrm{E}^{+}\right)+\mathrm{P}\right]}$

Here $\mathrm{C}_{\mu}$ and $\mathrm{E}$ are the constants in logarithmic law of the wall, $\kappa$ is the von Karman constant, Pr the Prandtl number, $\mathrm{y}^{+}$the nondimensional distance from the wall and $\mathrm{P}$ an empirical function defined by Djilali [22]. Flame radiation flux, $\dot{q}_{\text {rad }}$, over the liquid fuel surface is computed from a discrete representation of the radiative intensity which is obtained from a radiative transfer equation [20].

\subsection{Soot formation}

In fire plumes, the effect of soot production on radiation is significant via a mean absorption coefficient in a grey medium [20]. For simplicity, six bands are selected to give an accurate 
representation of the most important radiation bands of $\mathrm{CO}_{2}$ and $\mathrm{H}_{2} \mathrm{O}$ in addition to the soot formation. For the calculation of the grey or band-mean gas absorption coefficient, a narrowband model (RadCal) has been implemented in FDS [20].

Soot production is a highly complex subject due to the spatially-varying formation and oxidation processes in addition to the influences of turbulent fluctuations, temperature and fuel type. Nevertheless, a number of researchers [23, 24, 25] have had some success in identifying factors which allow simplified analysis. The current model is based on a classic principle of a Laminar Smoke Point (LSP) [25], to relate soot production to material properties. A fuel's smoke point is the maximum height of a laminar flame burning in air at which soot is not released from the flame tip.

A global soot formation model is incorporated into a flow calculation in a convection-diffusion equation for the soot mass fraction, $Y_{s}$.

$$
\frac{\partial \rho Y_{s}}{\partial t}+\frac{\partial\left(\rho u_{i} Y_{s}\right)}{\partial x_{j}}-\frac{\partial}{\partial x_{j}}\left(\frac{\mu_{t}}{S_{c}} \frac{\partial Y_{s}}{\partial x_{j}}\right)=\dot{\omega}_{s}
$$

The soot production rate is written as :

$$
\dot{\omega}_{\mathrm{s}}= \begin{cases}\dot{\omega}_{\mathrm{f}}-\dot{\omega} \mathrm{o} & \left(\mathrm{Z} \in\left[\mathrm{Z}_{\mathrm{so}}, \mathrm{Z}_{\mathrm{c}}\right]\right. \\ -\dot{\omega}_{\mathrm{o}} & \left(\mathrm{Z} \in\left[0, \mathrm{Z}_{\mathrm{so}}\right]\right.\end{cases}
$$

Two mixture fraction limits delimit the soot formation and oxidation regions. The incipient mixture fraction is $Z_{c}=0.15$, and the mixture fraction threshold where soot oxidation starts is $\mathrm{Z}_{\mathrm{so}}=0.1$. Soot formation is assumed to be controlled by second-order homogeneous gaseous reaction processes, and thus, is expressed as a function of the mixture fraction, $\mathrm{Z}$, and gas temperature, $\mathrm{T}$ :

$\dot{\omega}_{\mathrm{f}}=\operatorname{Af}_{\mathrm{f}} \rho^{2}\left(\frac{\mathrm{Z}-\mathrm{Z}_{\mathrm{st}}}{1-\mathrm{Z}_{\mathrm{st}}}\right) \mathrm{T}^{\gamma} \exp \left(-\mathrm{T}_{\alpha} / \mathrm{T}\right)$

Here the temperature exponent $\gamma=2.25$ and activation temperature $\mathrm{T}_{\alpha}=2000 \mathrm{~K}$ are assigned. The parameter to differentiate the sooting behaviour of different fuels is the pre-exponential factor, $\mathrm{A}_{\mathrm{f}}$, determined as $2.9 \times 10^{-5}$ and $3.1 \times 10^{-5}$, for heptane and dodecane, respectively. This parameter is reversely proportional to the measured smoke point height [25].

The soot oxidation in Eq.(8) is assumed to proceed through a single reaction step,

$\mathrm{C}_{\mathrm{s}}+\mathrm{O}_{2} \rightarrow \mathrm{CO}_{2}$

The soot oxidation is considered as a surface-area dependent mechanism, and its rate is evaluated from an Arrhenius expression for laminar flame [25]. In turbulent flame, soot oxidation can be significantly enhanced due to turbulence interactions. There remain some approximations by assuming that the mixing time in sub-grid scale is the limiting mechanism for soot oxidation, and its specific rate is expressed by the following EDC approach [26] :

$$
\dot{\omega}_{\mathrm{O}}=\frac{\mathrm{d} \rho \mathrm{Y}_{\mathrm{s}}}{\mathrm{dt}}=-\frac{\rho}{\tau_{\text {mix }}} \min \left(\mathrm{Y}_{\mathrm{s}}, \frac{\mathrm{Y}_{\mathrm{O} 2}}{\mathrm{v}}\right) \cdot \mathrm{H}_{\mathrm{eav}}\left(\mathrm{T}-\mathrm{T}_{\mathrm{lim}}\right)
$$

where $v$ denotes the stoichiometric coefficient for burning $1 \mathrm{~kg}$ of soot. The source term is multiplied by a Heaviside unit step function $\mathrm{H}_{\text {eav }}\left(\mathrm{T}-\mathrm{T}_{\text {lim }}\right)$, which is zero when its argument is negative $\left(\mathrm{T}<\mathrm{T}_{\mathrm{lim}}\right)$ and 1 when it is positive $\left(\mathrm{T}>\mathrm{T}_{\mathrm{lim}}\right)$. This implies that soot oxidation occurs as long as the local temperature is beyond a critical value of $\mathrm{T}_{\text {lim }}=700 \mathrm{~K}$. Note that such model contains no chemically kinetic mechanism to suppress homogeneous soot production by $\mathrm{O}_{2}$.

\subsection{Assessment of an ignition risk}


It is assumed that the combustion proceeds via two reaction steps :

$$
\begin{aligned}
& \mathrm{C}_{\mathrm{m}} \mathrm{H}_{\mathrm{n}}+\left(\frac{\mathrm{m}}{2}+\frac{\mathrm{n}}{4}\right) \mathrm{O}_{2} \rightarrow \mathrm{mCO}+\frac{\mathrm{n}}{2} \mathrm{H}_{2} \mathrm{O} \\
& \mathrm{CO}+\frac{1}{2} \mathrm{O}_{2} \rightarrow \mathrm{CO}_{2}
\end{aligned}
$$

The combustion rate in turbulent regime occurring at resolved scales is controlled by the eddy mixing rate. The local reaction rates of fuel and $\mathrm{CO}$ are calculated from an Eddy Dissipation Concept [26].

$$
\dot{\omega}_{\mathrm{i}}=\frac{\mathrm{d} \rho \mathrm{Y}_{\mathrm{i}}}{\mathrm{dt}}=-\frac{\rho}{\tau_{\text {mix }}} \min \left(\mathrm{Y}_{\mathrm{i}}, \frac{\mathrm{Y}_{\mathrm{O} 2}}{\mathrm{~s}}\right) \cdot \mathrm{H}_{\mathrm{eav}}\left(\mathrm{Y}_{\mathrm{O} 2}-\mathrm{Y}_{\mathrm{O} 2, \mathrm{lim}}\right)
$$

where s denotes the stoichiometric coefficient and $\mathrm{Y}_{\mathrm{i}}$ the fuel/CO mass fractions. The key timescale, $\tau_{\text {mix }}$, is supposed to be related approximately to the mixing time. This is based on the local state of the flow field associated to the processes of diffusion and subgrid-scale advection [20]. In the expression (14), the source term is multiplied by a Heaviside unit step function, $\mathrm{H}_{\text {eav }}\left(\mathrm{Y}_{\mathrm{O} 2}-\mathrm{Y}_{\mathrm{O} 2, \mathrm{lim}}\right)$, which is zero when its argument is negative $\left(\mathrm{Y}_{\mathrm{O} 2}<\mathrm{Y}_{\mathrm{O} 2 \text {,lim }}\right)$ and 1 when it is positive $\left(\mathrm{Y}_{\mathrm{O} 2}>\mathrm{Y}_{\mathrm{O} 2, \mathrm{lim}}\right)$. This implies that flame extinction occurs once the local oxygen concentration is below a critical value, $\mathrm{Y}_{\mathrm{O} 2, \mathrm{lim}}$. The critical value is evaluated from a control volume with a bulk temperature $T_{m}$ and a specific heat $C_{p}$ in addition to the adiabatic flame temperature $\mathrm{T}_{\mathrm{f}}$, as :

$$
\mathrm{Y}_{\mathrm{O} 2, \lim }=\frac{\mathrm{C}_{\mathrm{p}}\left(\mathrm{T}_{\mathrm{f}}-\mathrm{T}_{\mathrm{m}}\right)}{\Delta \mathrm{H}_{\mathrm{o}}}
$$

Here, $\Delta \mathrm{H}_{\mathrm{o}}$ equals to $13100 \mathrm{~kJ} / \mathrm{kg}$, corresponding to the amount of energy released per unit mass of oxygen consumed. This model shows also the feasibility for simulations of an ignition inside the extraction duct in closed, air vitiation environment. For example, when the fire has been established for sufficiently long, the elevated temperature of the hotter smoke layer near the ceiling contributes to a reduction in the critical value of the oxygen concentration. An ignition inside the extraction duct can occur if the local oxygen concentration is above the critical value due to a return of air from the dilution duct after the fire extinction in vitiated air enclosure. Note that such ignition model contains no chemically kinetic mechanism which is temperaturedependent. Thus, the time delay for ignition of the unburnt fuels cannot be accurately determined.

Due to lack of specie as $\mathrm{H}_{2}$ in the current combustion model, its concentration is derived from the conservation of the two chemical species, such as $\mathrm{C}_{\mathrm{m}} \mathrm{H}_{\mathrm{n}}$ and $\mathrm{CO}$, as the following relation [17]:

$$
[\mathrm{CO}]=\left[\mathrm{H}_{2}\right]+\sum\left[\mathrm{C}_{\mathrm{mH}}\right]
$$

The aim of this study is to verify if the auto-inflammation risk occurs when the unburnt fuel concentration is beyond the Low Flammability Limit (LFL) at the point of Auto-Ignition Temperature (AIT) [27]. The LFL $\mathrm{i}_{\mathrm{i}}$ of each fuel and the LFL of gas mixtures are determined as a function of the molar fraction $\mathrm{X}_{\mathrm{i}}$ of each fuel and the gas temperature with the following equations:

$$
\begin{aligned}
& \operatorname{LFLi}_{i}(\mathrm{~T})=\operatorname{LFLi}_{(}\left(\mathrm{T}_{0}\right)\left[1-\frac{\mathrm{T}-\mathrm{T}_{0}}{1300-\mathrm{T}_{0}}\right] \\
& \operatorname{LFL}(\mathrm{T})=100 \times\left[\sum_{\mathrm{i}} \frac{\mathrm{X}_{\mathrm{i}}}{\mathrm{LFLi}_{\mathrm{i}}(\mathrm{T})}\right]^{-1}
\end{aligned}
$$

where $i$ denotes the fuel type. The values of the AIT and LFL at $\mathrm{T}_{0}=25^{\circ} \mathrm{C}$ [27] for the four fuel species are summarized in Table 2. Note that the concentration of unburnt gas like $\mathrm{H}_{2}$ is used 
only for determining approximately the Low Flammability Limit (LFL), and has no influence on the prediction of the ignition risk.

Table 2. Values of the Low Flammability Limit (LFL) and the Auto-Ignition Temperature (AIT) for the major fuel species

\begin{tabular}{|l|l|l|l|l|}
\hline Parameter & $\mathrm{CO}$ & $\mathrm{H}_{2}$ & Heptane & Dodecane \\
\hline LFL $\left(\mathrm{T}_{0}=25^{\circ} \mathrm{C}\right)$ & $12.5 \%$ & $4 \%$ & $1.05 \%$ & $0.6 \%$ \\
\hline AIT $\left({ }^{\circ} \mathrm{C}\right)$ & 588 & 520 & 223 & 204 \\
\hline
\end{tabular}

\section{Results and discussion}

In LES as used in FDS, turbulence is modelled with an eddy viscosity attached to the grid size as a filter width. The convective length scale used in the liquid evaporation model is also attached to the mesh size. Globally, the numerical model uses the quantities that are mesh dependent. Choice of the grid size is guided by the smallest characteristic length of the liquid pool fire of $23 \mathrm{~cm}$ [20]. A structured mesh with a spatial resolution of $5 \mathrm{~cm}$ for the liquid pans of $23 \mathrm{~cm}$ and $40 \mathrm{~cm}$ is first employed, giving reasonable burning rate predictions. The calculations were performed using a grid resolution, $40 \times 40 \times 40$, for the enclosure with a length/height and width of $2 \mathrm{~m}$. The ducts have a square section of $0.2 \times 0.2 \mathrm{~m}^{2}$ with $4 \times 4$ cells. The extraction duct has a length of $1.1 \mathrm{~m}$ with 22 cells, and the dilution duct has a length of 2.5 $\mathrm{m}$ with 50 cells. The measured mass loss rate is used for activating the fire at the beginning of the simulation during $100 \mathrm{~s}$. The simulated physical time is about $2000 \mathrm{~s}$ in transient mode with a time-step of about $10^{-3} \mathrm{~s}$. In the current simulation, the computational domain consists of multiple meshes which can be treated with 16 processors through parallel processing of a Linux cluster with a CPU time in the order of 2 days. Refining the mesh size from $5 \mathrm{~cm}$ to $2.5 \mathrm{~cm}$ changes slightly the results. With each halving of the grid size, the time required for the simulation increases by a factor of $2^{4}=16$ (a factor of two for each spatial coordinate, plus time). The coarse grids used in the compartment fire simulations are adequate. This can be attributed to the fact that the compartment quickly fills with smoke, reducing the relative importance of the direct flame heat flux prediction. The layered structure in a compartment fire can be resolved using significantly fewer grid points compared to the structure of the flame. We focus on the chemical species and the gas temperature in transient mode mainly at the entrance of the extraction duct for assessing the ignition risk there.

Mass loss rates of heptane and dodecane were registered in the enclosure at various ventilation conditions, corresponding to 3 and 5 Air Change Per Hour (ACPH). The theoretical HRR inside the enclosure is derived by multiplying the measured mass loss rate by the energy released per kilogram of fuel completely consumed. Two fire regimes, such as well-ventilated and underventilated fires, as a function of ACPH can be distinguished. The typical trend of the HRR for heptane and dodecane with different boiling point, latent heat, etc. is described in Figs.2(a-e). For the heptane pan of $23 \mathrm{~cm}$ (cf. Fig.2a, b) and dodecane pan of $30 \mathrm{~cm}$ diameter (cf. Fig.2d) at 3 or $5 \mathrm{ACPH}$, the oxygen concentration initially present in the enclosure and the one supplied by mechanical ventilation entrains a sufficiently ventilated fire. For the heptane pan of $23 \mathrm{~cm}$, the increasing amount of oxygen entering the enclosure contributes to an increase of HRR from $35 \mathrm{~kW}$ at $3 \mathrm{ACPH}$ (cf. Fig.2a) to $50 \mathrm{~kW}$ at $5 \mathrm{ACPH}$ (cf. Fig.2b). The model correctly predicts the HRR as long as the fire is well ventilated, following the trend of the theoretical HRR because the reaction is almost complete. For the dodecane pan of $30 \mathrm{~cm}$ (cf. Fig.2d), the HRR rises progressively up to a peak value of $70 \mathrm{~kW}$. The HRR is over-predicted as compared to the theoretical one with an error below $15 \%$ as long as the fire becomes slightly under-ventilated during the fire growth period. 
Burning heptane pan of $30 \mathrm{~cm}$ (cf. Fig.2c) or dodecane pan of $40 \mathrm{~cm}$ (cf. Fig.2e) leads to underventilated fire. Evolution of the predicted and the theoretical HRRs can be said to follow three main stages : 1) the initial growth phase, in which burning is fuel-controlled with a stable flame; 2) the fully developed, post-flashover phase, in which burning is ventilation controlled with an unstable flame; and 3) the decay phase, in which burning returns to fuel-controlled one before extinction is achieved with burnout of the fuel load. As long as the fuel-controlled fire regime is maintained during the initial phase, there is a good fit between the predicted HRR and the theoretical one derived from the mass loss rate. The dodecane pan of $40 \mathrm{~cm}$ at $5 \mathrm{ACPH}$ conducts to a sharp increase of the HRR to $100 \mathrm{~kW}$ at the initial phase. Changing dodecane by heptane would change the fire dynamics, specifically during the initial phase (around $150 \mathrm{~s}$ ). Flashover is clearly identified by a rapid increase of HRR from 50 to $150 \mathrm{~kW}$ for the heptane pan of 30 $\mathrm{cm}$. Starting from $200 \mathrm{~s}$, oxygen concentration initially present and supplied by mechanical ventilation becomes insufficient to maintain an intensive combustion; the fire becomes progressively under-ventilated with an accumulation of unburnt gases. Once the hotter smoke spreads towards the liquid base, the lowed oxygen vitiation induces an unstable flame due to the ignition/extinction of the liquid fuel pan. Oscillations of the HRR observed experimentally due to an unstable flame in under-ventilated conditions are apparently not well captured by the model with a discrepancy up to $50 \%$. It should be noted that for the tests, the liquid fuel was completed with $10 \mathrm{~cm}$-height of water in the pool, and the depth of fuel added was $10 \mathrm{~cm}$-height. The HRR is more gradual in the simulations than in the experiments because the liquid is treated as a solid and the evaporation model is applied on a cell by cell basis. This kind of modelling allows the pool to burn out in the middle before all fuel is consumed. In the experiments, the flowing liquid would remain as a large burning surface until the fuel is consumed. Convective motions inside the liquid are likely to be important in explaining the experimental HRR profiles. The one-dimensional heat transfer model does not seem to accurately predict the temperature distribution within the liquid.

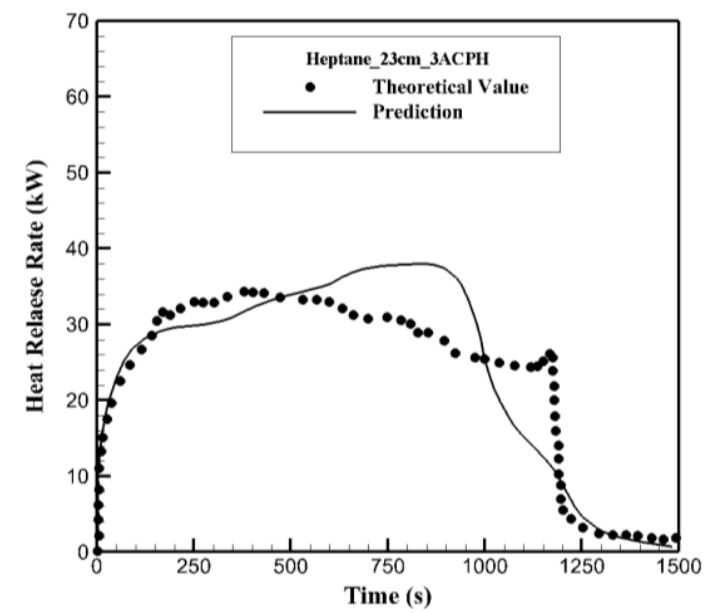

2a) Heptane pan of $23 \mathrm{~cm}$ at $3 \mathrm{ACPH}$ corresponding to a sufficiently ventilated fire within $10 \%$ error 


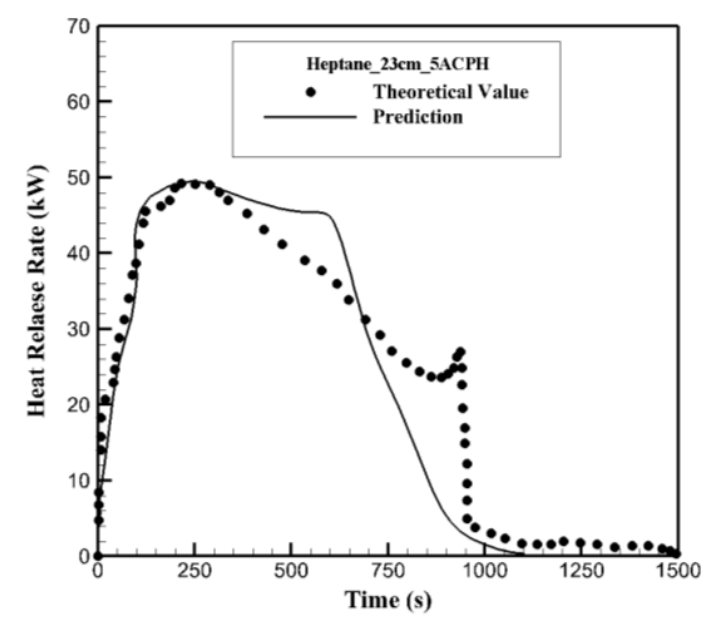

2b) Heptane pan of $23 \mathrm{~cm}$ at $5 \mathrm{ACPH}$ corresponding to a sufficiently ventilated fire within $20 \%$ error

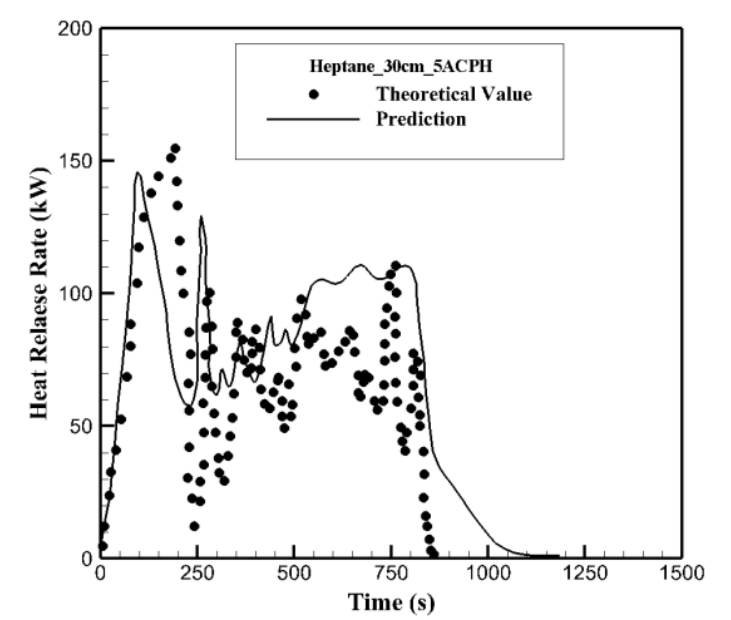

2c) Heptane pan of $30 \mathrm{~cm}$ at $5 \mathrm{ACPH}$ corresponding to an under-ventilated fire within $50 \%$ error

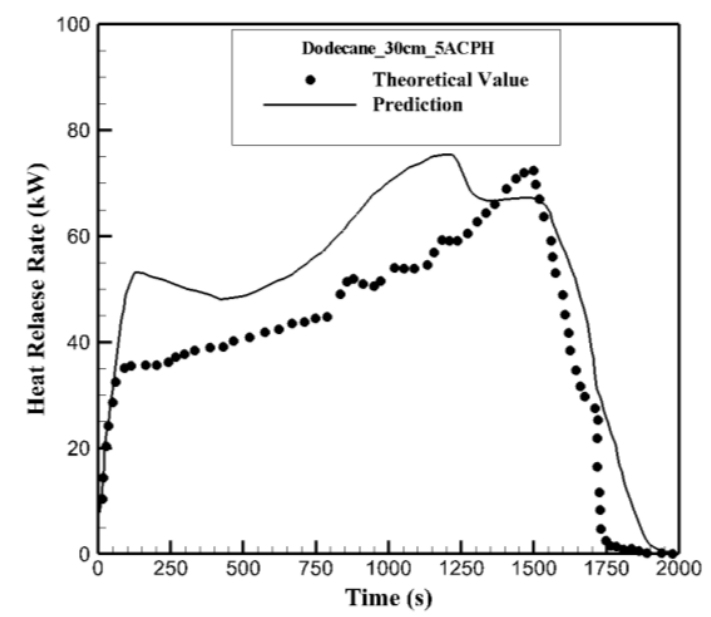

2d) Dodecane pan of $30 \mathrm{~cm}$ at $5 \mathrm{ACPH}$ corresponding to a sufficiently ventilated fire within $25 \%$ error 


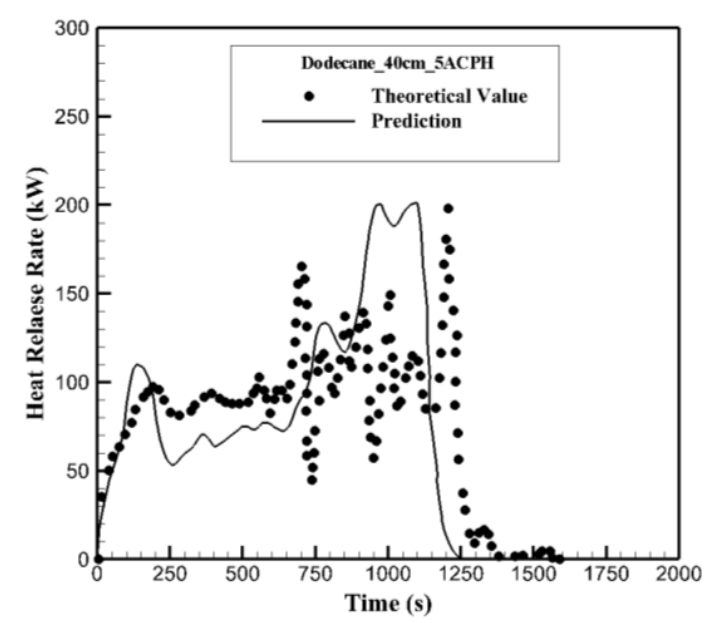

2e) Dodecane pan of $40 \mathrm{~cm}$ at $5 \mathrm{ACPH}$ corresponding to an under-ventilated fire within $35 \%$ error

Figure 2. Comparison between the calculated HRR and the theoretical one with a discrepancy varying from $10 \%$ to $50 \%$ as a function of the ventilation condition or fuel type

Comparison of the numerical results to the measured oxygen concentration at the entrance of the extraction duct is presented in Figs.3(a-e). The first situation includes well ventilated fires for the heptane pan of $23 \mathrm{~cm}$ diameter (cf. Fig.3a, b). During the initial fire growth stage, there is sufficient oxygen available to maintain a stable flame attached to the liquid surface and a good agreement between the prediction and the experiment is obtained. Starting from $800 \mathrm{~s}$, the oxygen starvation begins for an oxygen concentration of around $11 \%$ and the oxygen-lean/fuelrich hot upper layer is being formed near the ceiling. For the dodecane pan of $30 \mathrm{~cm}$ diameter (cf. Fig.3d), the measured oxygen starvation begins from $1400 \mathrm{~s}$, and the predicted oxygen concentration is lower than the measured one. In the numerical simulation, starting from $250 \mathrm{~s}$, oxygen is quickly consumed due to the excessive pyrolysis products in the vicinity of the fire source, resulting in a quick oxygen starvation at the extraction duct. This highlights the shortcoming of the use of a fast combustion model, irrespective to the chemical kinetic depending on the gas temperature. At $5 \mathrm{ACPH}$, for the heptane pan of $30 \mathrm{~cm}$ (cf. Fig.3c) and the dodecane pan of $40 \mathrm{~cm}$ (cf. Fig.3e), the fire becomes very under-ventilated with oxygen concentration around 7\%; the unstable flame takes place and the fire finally stops due to insufficient amount of oxygen with a concentration of $5 \%$. When the fire extinction occurs, the rise of the $\mathrm{O}_{2}$ concentration at the entrance of the extraction duct is mainly attributed to an accumulation of oxygen supplied by mechanical ventilation. During the fire decaying phase, starting from $1200 \mathrm{~s}$, the prediction follows approximately the experimental trend and is better for the dodecane pan. 


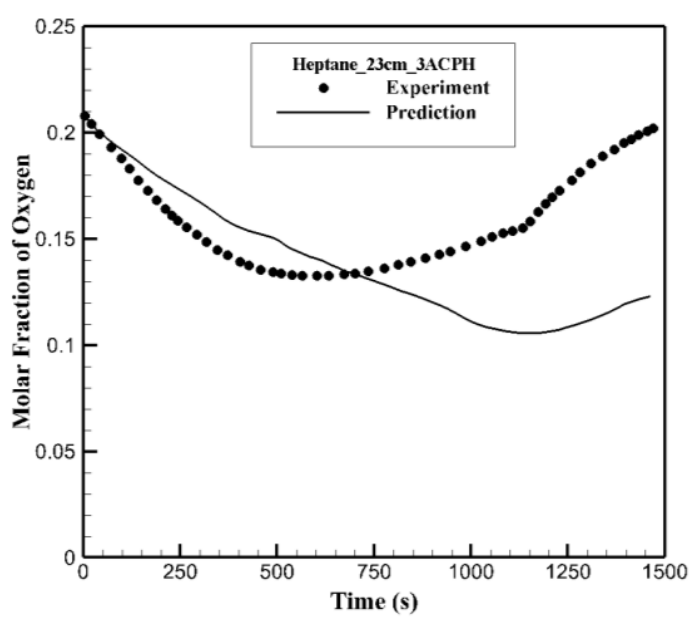

3a) Heptane pan of $23 \mathrm{~cm}$ at $3 \mathrm{ACPH}$ corresponding to a sufficiently ventilated fire within $30 \%$ error

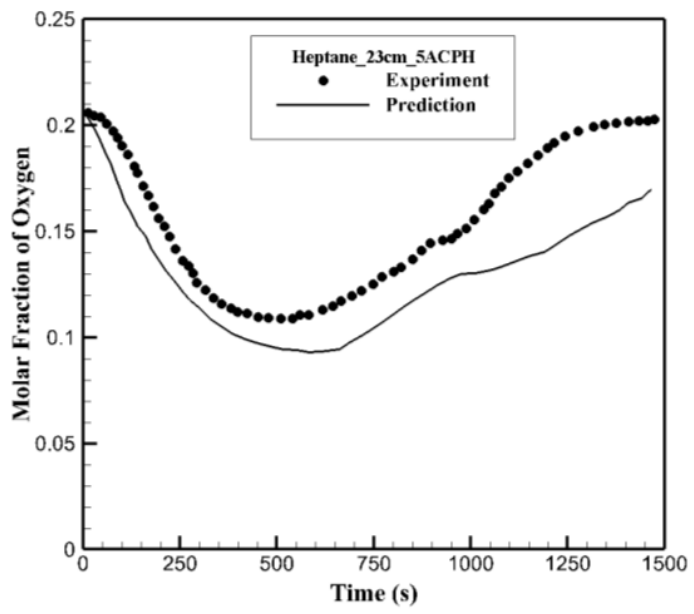

3b) Heptane pan of $23 \mathrm{~cm}$ at $5 \mathrm{ACPH}$ corresponding to a sufficiently ventilated fire within $25 \%$ error

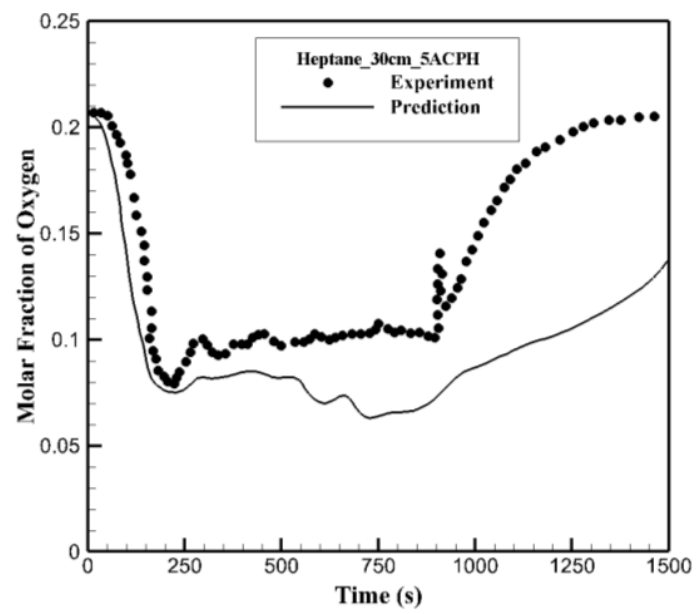

3c) Heptane pan of $30 \mathrm{~cm}$ at $5 \mathrm{ACPH}$ corresponding to an under-ventilated fire within $30 \%$ error 


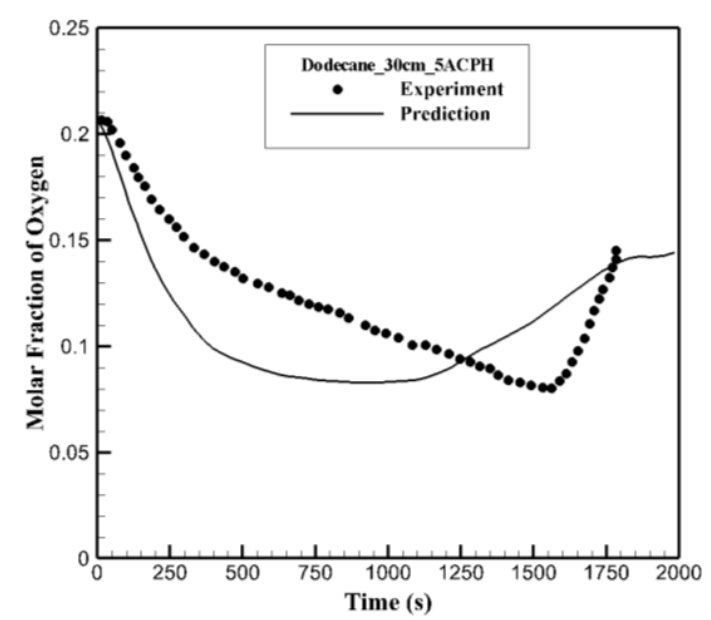

3d) Dodecane pan of $30 \mathrm{~cm}$ at $5 \mathrm{ACPH}$ corresponding to a sufficiently ventilated fire within $18 \%$ error

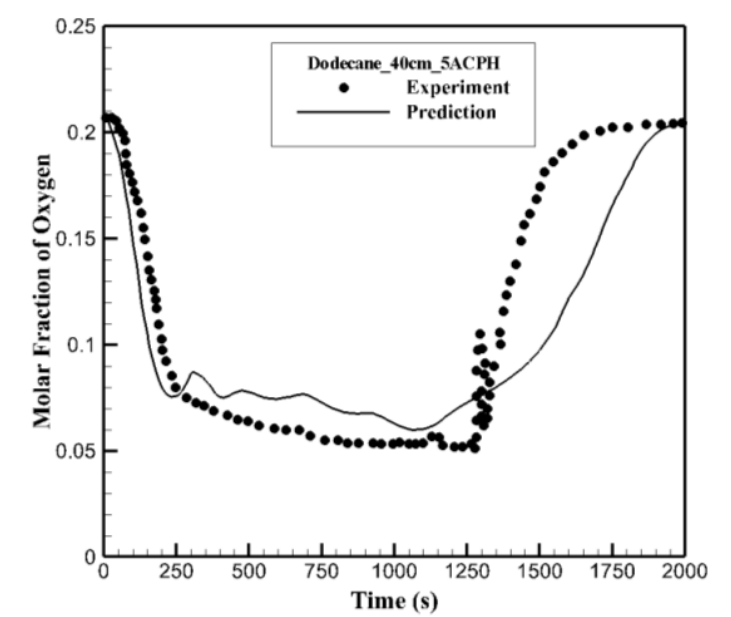

3e) Dodecane pan of $40 \mathrm{~cm}$ at $5 \mathrm{ACPH}$ corresponding to an under-ventilated fire within $50 \%$ error

Figure 3. Comparison between the calculated oxygen concentration and the measured one with a discrepancy varying from $18 \%$ to $50 \%$ as a function of the ventilation condition or fuel type

The predicted and measured carbon monoxide, hydrogen and primary fuel concentrations at the entrance of the extraction duct for the dodecane pan of $40 \mathrm{~cm}$ are analysed in Figs.4(a-c). Occurrence of an auto-ignition in this case was identified experimentally. The first period to $200 \mathrm{~s}$, corresponds to sufficiently ventilated conditions with a low carbon monoxide production (cf. Fig.4a), because there is sufficient oxygen available for its oxidation into $\mathrm{CO}_{2}$. The underventilated condition takes place for an oxygen concentration of around $10 \%$ (cf. Fig.3e) in the second period between 250 and $750 \mathrm{~s}$, and carbon monoxide production remains the more important. Carbon monoxide production reaches a maximum in the last period around $1200 \mathrm{~s}$ in the very under-ventilated conditions for an oxygen concentration of around 7\% (cf. Fig.3e). This is attributed to the excess combustible gas from pyrolysis of the liquid fuel enhanced by the relatively high temperature for many minutes in the vitiated air enclosure. The calculated molar fraction of $\mathrm{CO}$ reaches a peak value of $3.5 \%$ at the time of $500 \mathrm{~s}$, whereas the measured one reaches a peak value of $2.5 \%$ with a time delay of $1200 \mathrm{~s}$.

A correlation is proposed in the literature [17] to evaluate the carbon monoxide concentration as a function of the oxygen concentration, which presents three parts as follows: 


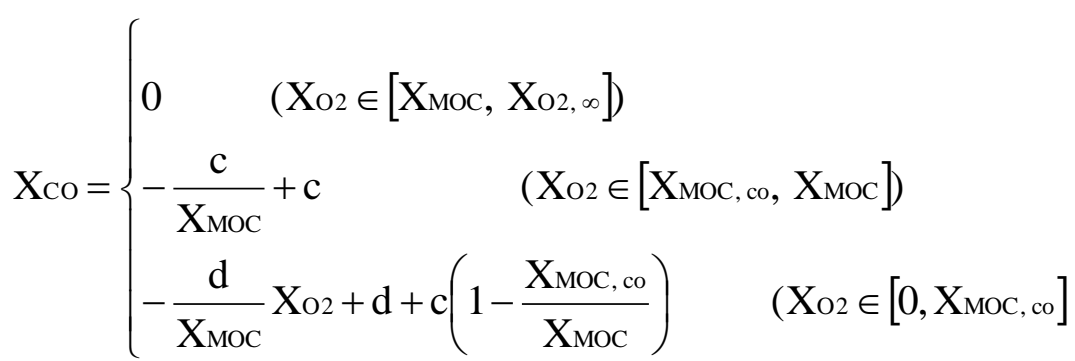

Here $\mathrm{X}_{\mathrm{MOC}}$ represents the Minimum Oxygen Concentration for a nearly complete reaction of a given fuel, and $\mathrm{X}_{\mathrm{MOC} \text {,co }}$ for oxidation of $\mathrm{CO}$ to $\mathrm{CO}_{2}$. The empirical constants $\mathrm{c}$ and $\mathrm{d}$ slightly depend on the fuel type, as given in Table 3. The CO production is zero when the oxygen concentration is beyond $\mathrm{X}_{\mathrm{MOC}}$, corresponding to a sufficiently ventilated condition. The range of oxygen concentration between $\mathrm{X}_{\mathrm{MOC} \text {,co }}$ and $\mathrm{X}_{\mathrm{MOC}}$ implies an under-ventilated condition with a significant $\mathrm{CO}$ production due to an incomplete oxidation reaction. The oxygen concentration below $\mathrm{X}_{\mathrm{MOC}, \mathrm{co}}($ about $7 \%$ ) results in a maximum $\mathrm{CO}$ production, implying a very underventilated condition. A relationship is also proposed in the literature [17] to relate the unburnt fuel concentration with the $\mathrm{CO}$ one, as follows:

$[\mathrm{CO}]=2 \sum\left[\mathrm{Cm}_{\mathrm{n}}\right]$

The $\mathrm{H}_{2}$ concentration is derived from the conservation of the chemical species as Eq.(16).

Table 3. Empirical constants used in the correlation (19) for CO concentration

\begin{tabular}{|l|l|l|}
\hline Parameter & Heptane & Dodecane \\
\hline $\mathrm{X}_{\mathrm{CMO}}$ & $11.55 \%$ & $11.1 \%$ \\
\hline $\mathrm{X}_{\mathrm{CMO}, \mathrm{co}}$ & $6.25 \%$ & $6.25 \%$ \\
\hline $\mathrm{c}$ & 1.96 & 1.98 \\
\hline $\mathrm{d}$ & 8 & 8 \\
\hline
\end{tabular}

Based on the predicted oxygen concentration (cf. Fig.3e), a trend of the molar fraction of the species as $\mathrm{H}_{2}, \mathrm{CO}$ and primary fuel, derived from the correlations $(16,19,20)$ is also added in Figs.4(a-c). As compared with the measurement, the correlation (16) for the hydrogen concentration is with acceptable accuracy, while the correlations $(19,20)$ under-estimate the $\mathrm{CO}$ and primary fuel concentrations. The difference between the prediction, correlation and experiment for the amplitudes and the temporal variation of chemical species originates from the inherent complexity in chemical reaction.

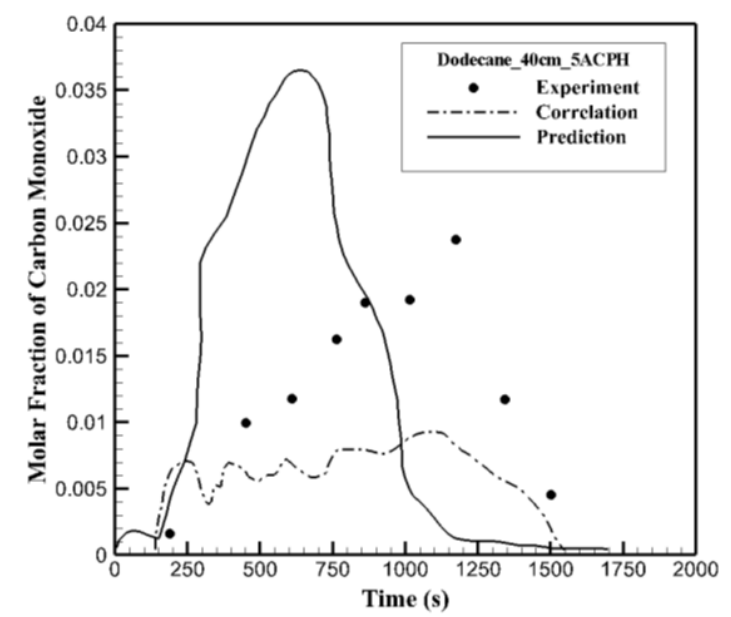

4a) Carbon monoxide concentration within $40 \%$ error 


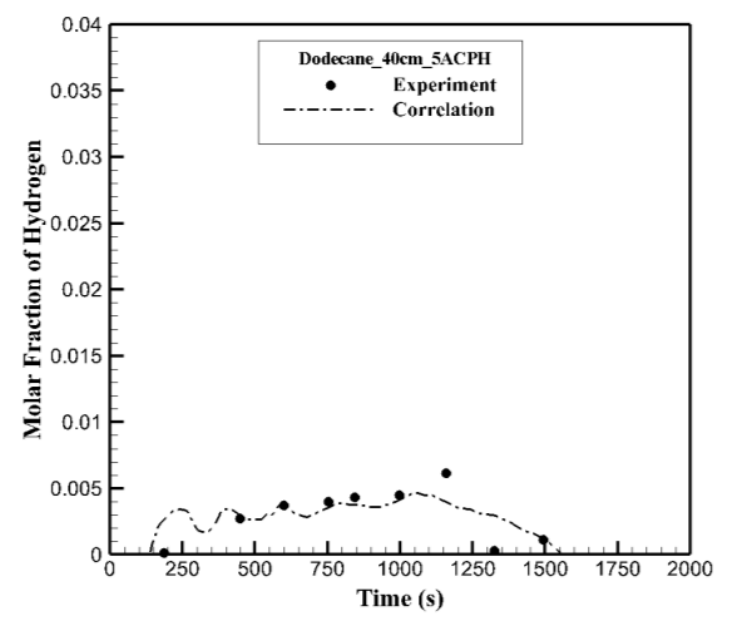

4b) Hydrogen concentration within $2 \%$ error

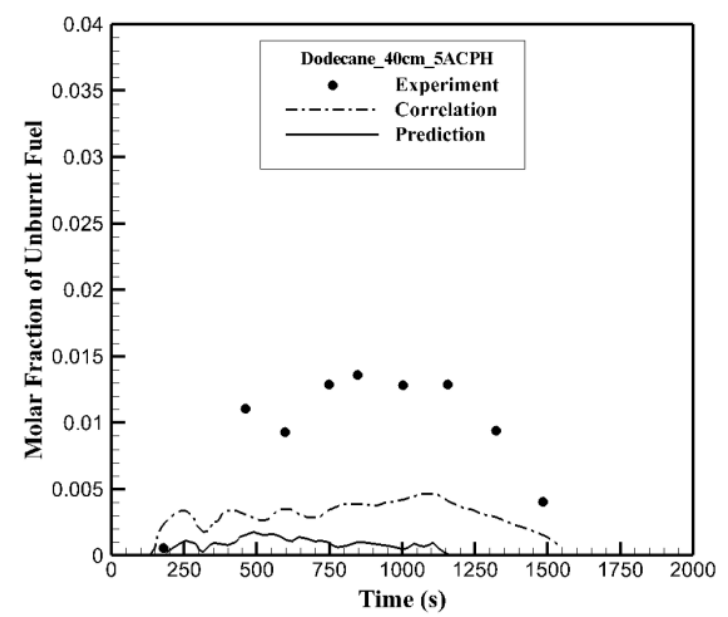

4c) Primary fuel concentration within $80 \%$ error

Figure 4. Comparison between the calculated and the measured chemical species concentrations at entrance of the extraction duct with a discrepancy varying from $2 \%$ to $80 \%$ for dodecane pan size of $40 \mathrm{~cm}$ at $5 \mathrm{ACPH}$

An ignition represents very complex chemistry and physical processes, there is still a lack of knowledge for complete understanding of such phenomenon. Globally, issues involved for occurrence of auto-ignition near the extraction duct are amount of accumulated unburnt volatiles above LFL, gas temperature above $350^{\circ} \mathrm{C}$, oxygen concentration above $10 \%$, and phenomena leading to fire extinction with an oxygen concentration below $5 \%$ in the enclosure. As illustrated in Fig.5a for the dodecane pan of $40 \mathrm{~cm}$ at $5 \mathrm{ACPH}$, starting from $250 \mathrm{~s}$, a stratified hotter unburnt fuels layer with a concentration beyond the Lower Flammability Limit (LFL) is formed at entrance of the extraction duct. Analyse of the predicted and measured gas temperature at the entrance of the extraction duct is performed in Fig.5b in addition to the global equivalence ratio, as the expression, $\phi=\dot{\mathrm{m}}_{\mathrm{F}} \mathrm{s} / \dot{\mathrm{m}}_{\mathrm{A}}$ where $\dot{\mathrm{m}}_{\mathrm{F}}$ denotes the fuel supply rate $(\mathrm{kg} / \mathrm{s}), \dot{\mathrm{m}}_{\mathrm{A}}$ the mass inflow rate of air $(\mathrm{kg} / \mathrm{s})$, and s stoichiometric coefficient. In the early stages of a fire, the gas temperature reaches the Auto-Ignition Temperature (about $220^{\circ}$ ) of the primary fuel (dodecane or heptane, see Tab.2). It seems that this temperature level is not high enough for triggering an auto-ignition of the mixture of unburnt gases (hydrocarbons, $\mathrm{CO}, \mathrm{H}_{2}$ ) and air inside the extraction duct. However, we lack the ability to accurately quantify the auto-ignition temperature of a mixture of unburnt fuel and air through bench-scale experiments, which is chemical composition-dependent. With a long time delay of about $1000 \mathrm{~s}$, the energy released per mass of oxygen consumed allows to raise the smoke temperature above $350^{\circ} \mathrm{C}$, which seems 
high enough for an auto-ignition of a mixture of the unburnt gases and air. However, during this stage, the large vaporized fuel due to enhanced heat transfer does not completely contribute to the heat release, thus forming significant unburnt gases with a concentration considerably higher than LFL. Consequently, there is insufficient oxygen available near the ceiling for triggering the ignition. Occurrence of flame extinction in vitiated air enclosure with an oxygen concentration below 5\% makes a sudden decrease of the pressure level inside enclosure due to cooling effects. This induces a sudden supply of fresh air from dilution duct characterized by a sharp increase of oxygen concentration, which can be identified from the evolution of the oxygen (cf. Fig.3e) at the extinction point of about $1250 \mathrm{~s}$. This provides a sufficient oxygen concentration with a molar fraction of about $10 \%$ for triggering the ignition of a hotter fuel-air mixture with a temperature above $350^{\circ} \mathrm{C}$ near the extraction duct. Note that the predicted ignition delay is about $1150 \mathrm{~s}$, which is shorter than the ignition time of about $1250 \mathrm{~s}$ in the experiments [16]. Besides, by using the thermocouples, accurate identification of a typical flame temperature in space and time during the unburnt gas ignition is quite difficult. This may be attributed to the discrepancy between the predicted temperature peak of $550^{\circ} \mathrm{C}$ and the measured one of $420^{\circ} \mathrm{C}$. Evolution of the temperature of unburnt gases (cf. Fig.5b) as a function of $\phi$ indicates that the equivalent ratio higher than 1.5 represents a set of dangerous conditions when the fire has been established for sufficiently long, as any return of air from dilution duct could lead to spontaneous ignition near the extraction duct after extinction in enclosure.

The empirical, numerical and experimental approaches suggest that the ignition phenomena near the extraction duct can be identified by a sharp decrease of the molar fraction of unburnt fuels towards a stoichiometric fuel-air mixture, and an elevated temperature peak. Evolution of the molar fraction of unburnt fuels for the dodecane pan of $40 \mathrm{~cm}$ at $3 \mathrm{ACPH}$ is presented in Fig.6. It is found that the decreasing amount of air entering the enclosure at $3 \mathrm{ACPH}$ contributes to a significant increase of the molar fraction of unburnt fuels near the extraction duct. With a time delay of $1600 \mathrm{~s}$, the predicted molar fraction of unburnt fuels decreases sharply towards LFL due to air dilution. This implies that for a given dodecane pan of $40 \mathrm{~cm}$, a decrease of ACPH from 5 to 3 contributes to an increase in the delay time for occurrence of an ignition, corresponding approximately to the experimental trend. The heptane pan of $30 \mathrm{~cm}$ (cf. Fig.7) at $3 \mathrm{ACPH}$ contributes to an important formation of the stratified unburnt fuels layer at the extraction duct with a predicted time delay of about $1300 \mathrm{~s}$ for occurrence of the ignition there. Such auto-ignition was identified experimentally by visual identification of fire with a probability of $50 \%$ due to the heat leakage through the walls of the experimental facility. When the compartment is more heat-tight by using an insulating material, the auto-ignition occurs for each fire tests. The numerical simulation and the empirical correlation are qualitatively promising for the risk assessment of unburnt gases ignition, but identification of the ignition time delay and location controlled by the fire scenario is within $15-30 \%$ error. 


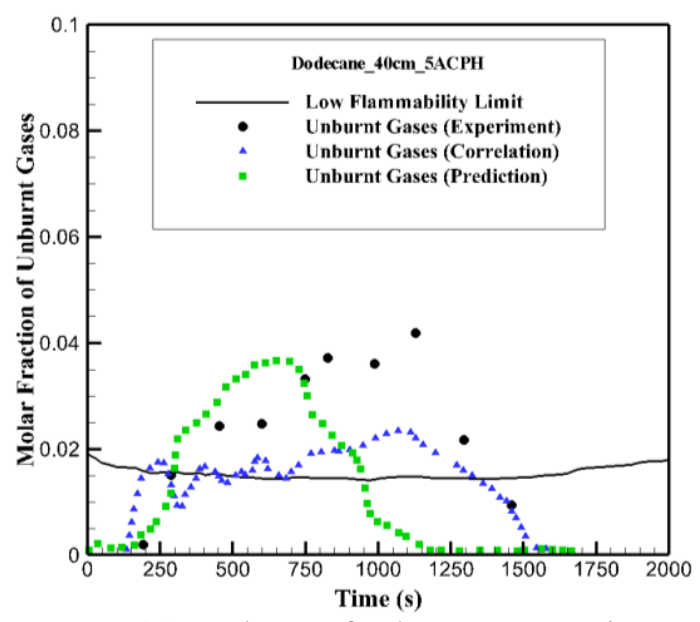

5a) Unburnt fuels concentration within 5\% error between prediction and measurement

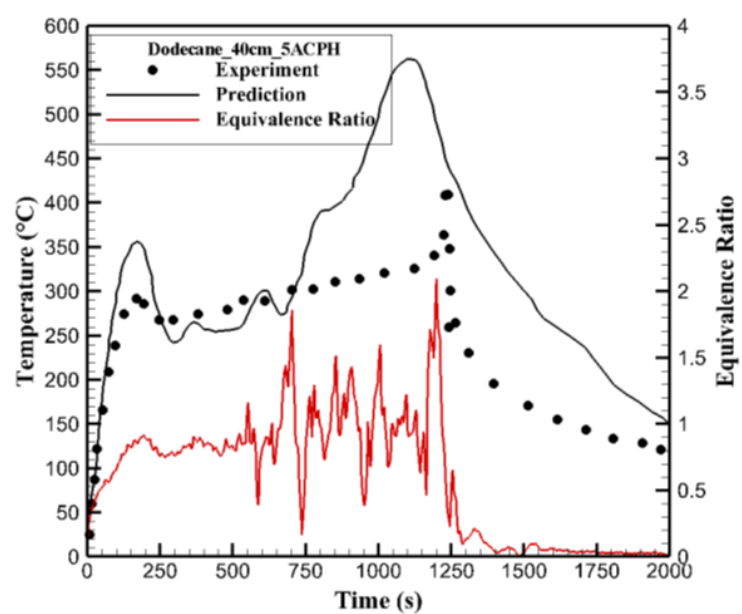

5b) Gas temperature within $20 \%$ error between prediction and measurement

Figure 5. Risk assessment of unburnt gases ignition near the entrance of the extraction duct for dodecane pan of $40 \mathrm{~cm}$ at $5 \mathrm{ACPH}$

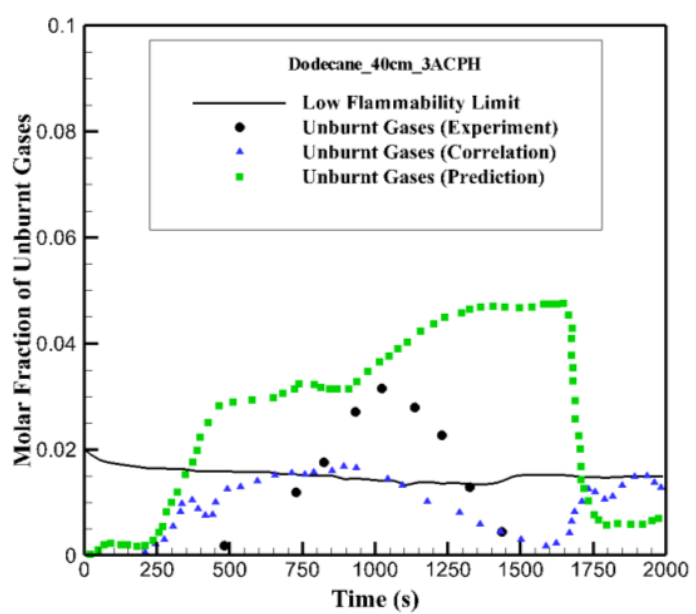

Figure 6. Comparison between experiment and prediction for the molar fraction of unburnt fuels within $30 \%$ error for dodecane pan of $40 \mathrm{~cm}$ at $3 \mathrm{ACPH}$ 


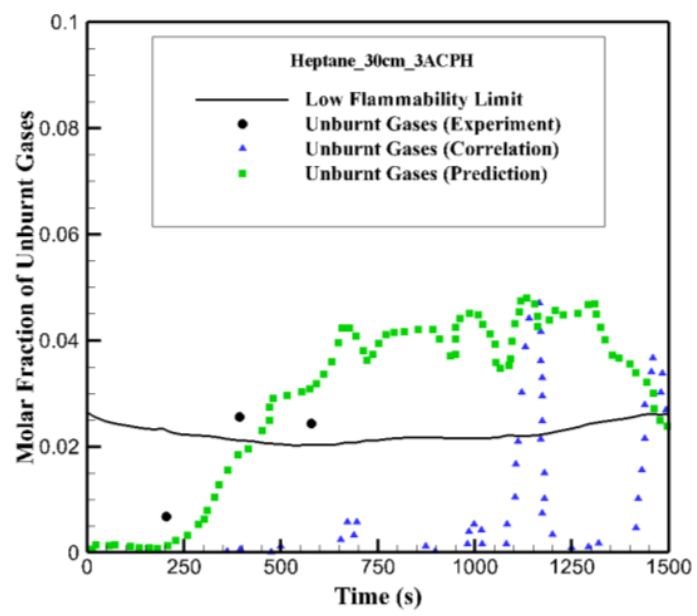

Figure 7. Comparison between experiment and prediction for the molar fraction of unburnt fuels within $60 \%$ error for heptane pan of $30 \mathrm{~cm}$ at $3 \mathrm{ACPH}$

The heptane pan of $23 \mathrm{~cm}$ (cf. Fig.8a, b) and the dodecane pan of $30 \mathrm{~cm}$ (cf. Fig. $8 \mathrm{c}$ ) correspond to well ventilated condition with a global equivalent ratio lower than unit during the fire. The reaction is almost complete in such situation without ignition risk near the extraction duct. For heptane pan of $23 \mathrm{~cm}$ at $3 \mathrm{ACPH}$ (cf. Fig.8a), the gas temperature at the entrance of the extraction duct (TE1, cf. Fig.1c) increases progressively during the fire growth period, reaching a plateau with a value of $200^{\circ} \mathrm{C}$ in a quasi-steady period. Similar trend is found for the same pan at $5 \mathrm{ACPH}$, but the gas temperature reaches a peak value of $230^{\circ} \mathrm{C}$ due to the enhanced convective transport. A good agreement between the predicted and the measured gas temperature is found for the heptane pan of $23 \mathrm{~cm}$. For the dodecane pan of $30 \mathrm{~cm}$ at $5 \mathrm{ACPH}$ (cf. Fig.8c), the gas temperature increases monotonously up to fire extinction. The heptane pan of $30 \mathrm{~cm}$ at $5 \mathrm{ACPH}$ (cf. Fig.8d) corresponds to under-ventilated fire with a global equivalent ratio higher than unit. Such under-ventilated condition induces an unstable flame due to lowered oxygen vitiation in the enclosure, characterized by a large oscillation of the gas temperature varying from $250^{\circ} \mathrm{C}$ to $350^{\circ} \mathrm{C}$.

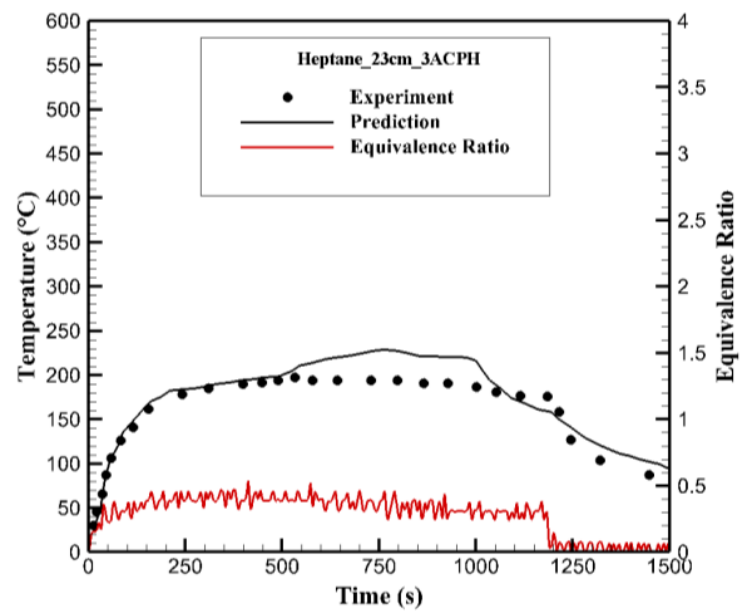

8a) Heptane pan of $23 \mathrm{~cm}$ at $3 \mathrm{ACPH}$ corresponding to a sufficiently ventilated fire within 5\% error 


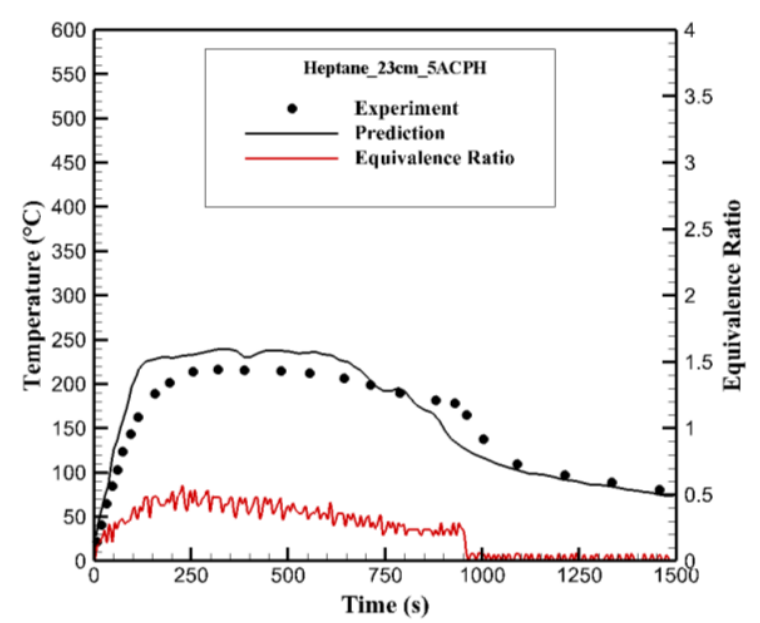

8b) Heptane pan of $23 \mathrm{~cm}$ at $5 \mathrm{ACPH}$ corresponding to a sufficiently ventilated fire within $5 \%$ error

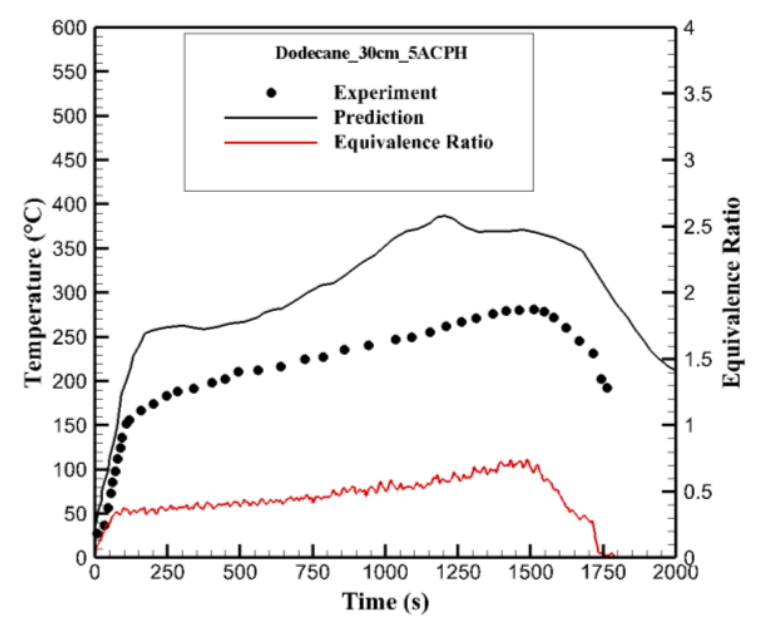

8c) Dodecane pan of $30 \mathrm{~cm}$ at $5 \mathrm{ACPH}$ corresponding to a sufficiently ventilated fire within $35 \%$ error

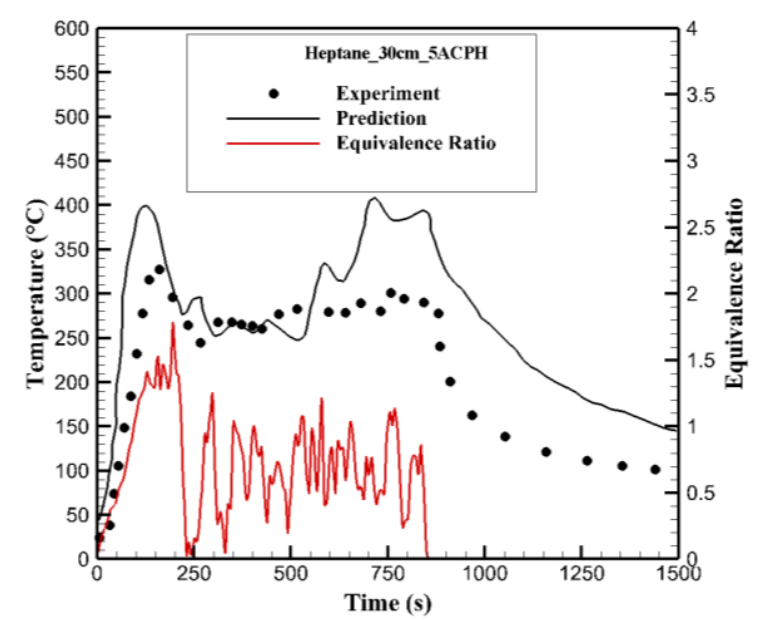

8d) Heptane pan of $30 \mathrm{~cm}$ at $5 \mathrm{ACPH}$ corresponding to an under-ventilated fire within $30 \%$ error Figure 8. Comparison between the calculated and the measured temperature at the entrance of the extraction duct with a discrepancy varying from $5 \%$ to $35 \%$ as a function of the fuel type

As an illustration, the gas temperature in the dilution duct (TD7, cf. Fig.1c) is presented in Figs.9(a-e) for heptane and dodecane pans. The heptane pan of $23 \mathrm{~cm}$ (cf. Fig.9a, b) and the dodecane pan of $30 \mathrm{~cm}$ (cf. Fig.9d), correspond to a well ventilated condition with a gas 
temperature below $200^{\circ} \mathrm{C}$ inside the dilution duct. An increase of heptane pan size from 23 (cf. Fig.9b) to $30 \mathrm{~cm}$ (cf. Fig.9c) leads to a rise of gas temperature from $120^{\circ} \mathrm{C}$ to $230^{\circ} \mathrm{C}$ due to accumulation of the hotter gas inside the dilution duct, following the experimental trend. Both the prediction and the experiment indicate that the onset of auto-ignition inside the extraction duct for the heptane pan of $30 \mathrm{~cm}$ (cf. Fig.9c) and the dodecane pan of $40 \mathrm{~cm}$ (cf. Fig.9e) results in the rather high temperature of about $250-300^{\circ} \mathrm{C}$ even in the dilution duct.

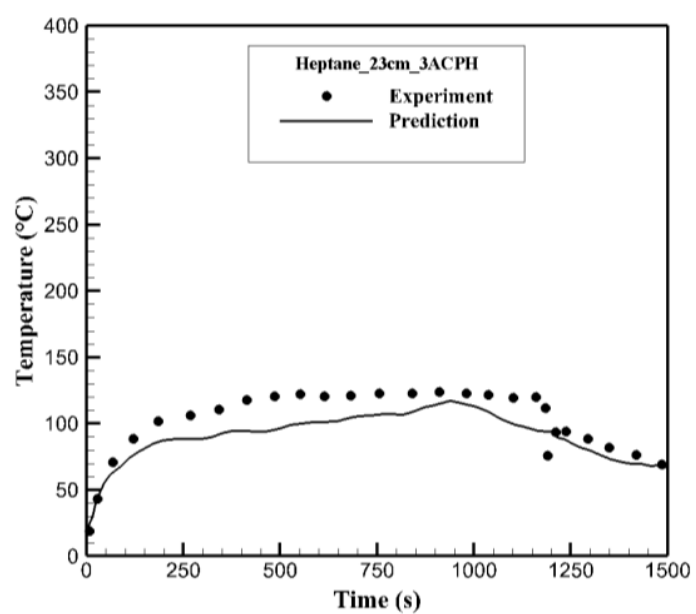

9a) Heptane pan of $23 \mathrm{~cm}$ at $3 \mathrm{ACPH}$ corresponding to a sufficiently ventilated fire within $5 \%$ error

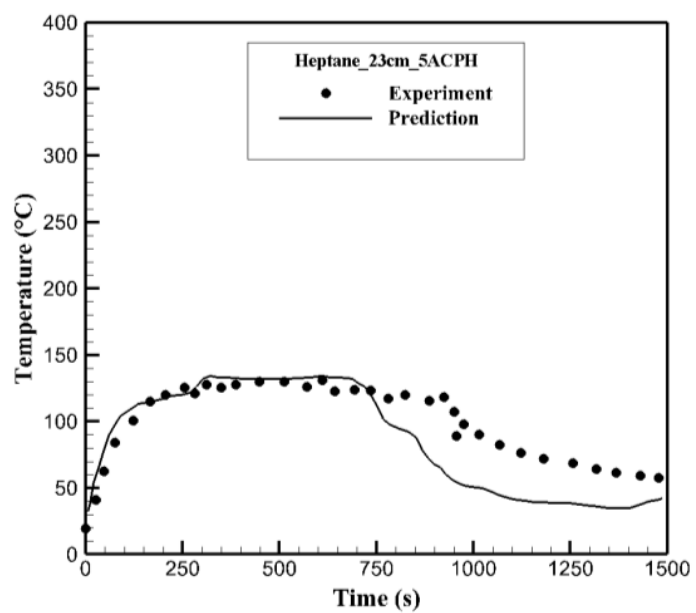

9b) Heptane pan of $23 \mathrm{~cm}$ at $5 \mathrm{ACPH}$ corresponding to a sufficiently ventilated fire within $10 \%$ error

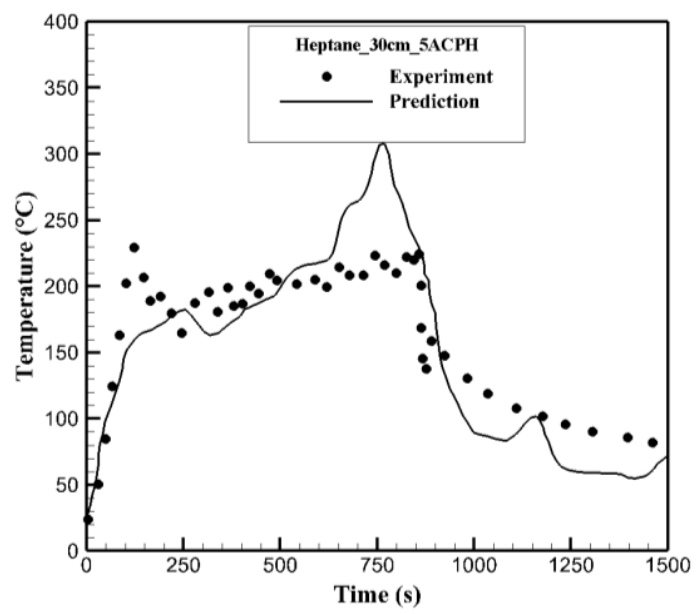

9c) Heptane pan of $30 \mathrm{~cm}$ at $5 \mathrm{ACPH}$ corresponding to an under-ventilated fire within $30 \%$ error 


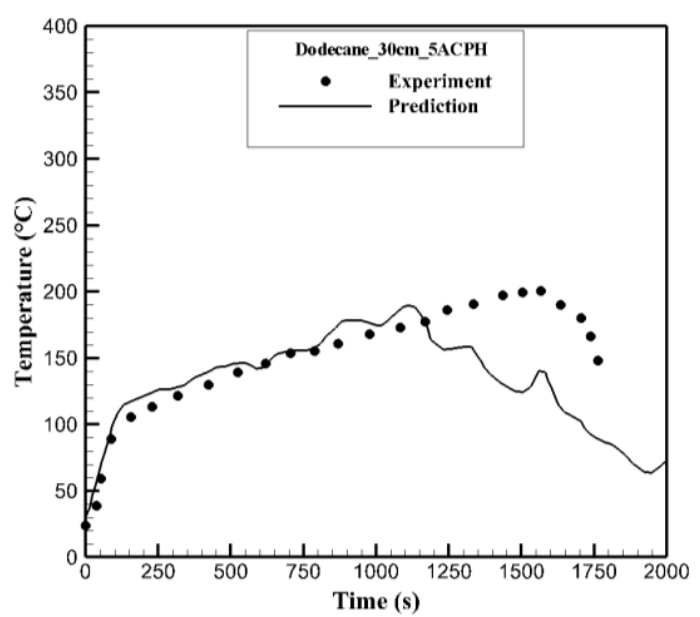

9d) Dodecane pan of $30 \mathrm{~cm}$ at $5 \mathrm{ACPH}$ corresponding to a sufficiently ventilated fire within $10 \%$ error

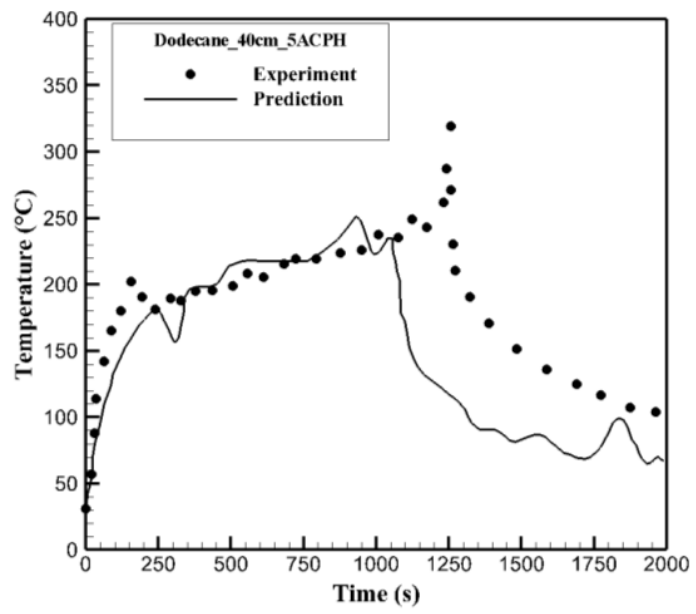

9e) Dodecane pan of $40 \mathrm{~cm}$ at $5 \mathrm{ACPH}$ corresponding to an under-ventilated fire within $16 \%$ error

Figure 9. Comparison between the calculated and the measured gas temperatures inside the dilution duct with a discrepancy varying from $5 \%$ to $30 \%$ as a function of the ventilation condition or fuel type

Comparison of the numerical results to the measured local gas temperature in the vicinity of the fire source (TL1_5, cf. Fig.1b, c) is performed in Figs.10(a-e) for heptane and dodecane pan size varying from $23 \mathrm{~cm}$ to $40 \mathrm{~cm}$ at 3 or $5 \mathrm{ACPH}$. It seems that evolution of the gas temperature depends strongly on the compartment fire dynamics regime, such as well- or under-ventilated fire. In well ventilated condition as for heptane pan of $23 \mathrm{~cm}$ (cf. Fig.10a, b), the fire behaved in a very consistent manner and the temperature remains relatively high with a value of $500^{\circ} \mathrm{C}$ for many minutes. An increase of the ACPH from 3 to 5 contributes to a reduction of $50^{\circ} \mathrm{C}$ in the gas temperature. The model is found to under-predict the temperature as compared to the experimental data at low ventilation rate of $3 \mathrm{ACPH}$, whereas to agree with measurement at 5 $\mathrm{ACPH}$. Both the experimental data and the prediction show that for a given $\mathrm{ACPH}$, an increase of pan size from 23 (cf. Fig.10b) to $30 \mathrm{~cm}$ (cf. Fig.10c) contributes to an increase of gas temperature from $500^{\circ} \mathrm{C}$ to $800^{\circ} \mathrm{C}$ due to enhanced fire plume dynamics. For the dodecane pan of $30 \mathrm{~cm}$ at $5 \mathrm{ACPH}$ (cf. Fig.10d), the gas temperature reaches sharply a peak point of $700^{\circ} \mathrm{C}$ during the initial fire growth period due to a considerable increase of the HRR, and then, approaches a plateau in a quasi-steady period. For the dodecane pan of $40 \mathrm{~cm}$ (Fig.10e), the predicted temperature trend corresponds well with the measured one solely during the initial 
fire growth period. Generally, the model exhibit a more conservative behavior, and the discrepancies between the experimental data and the prediction are mainly attributed to the over-prediction of the HRR in the under-ventilated conditions.

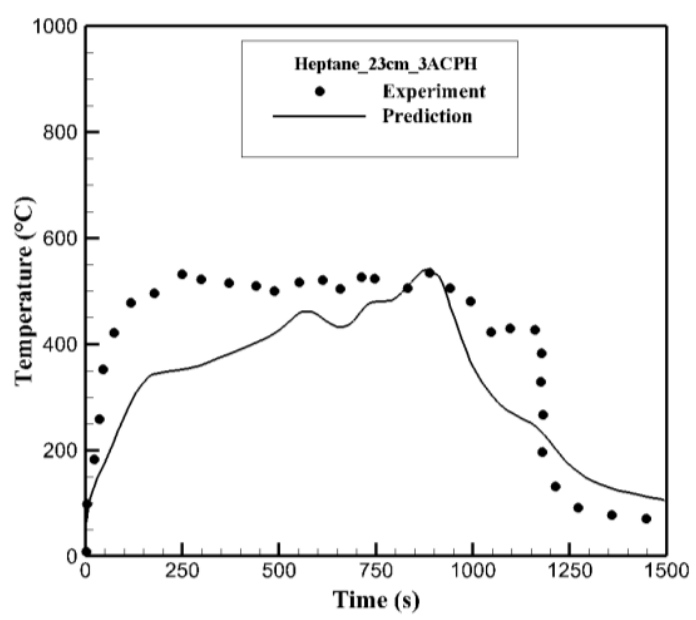

10a) Heptane pan of $23 \mathrm{~cm}$ at $3 \mathrm{ACPH}$ corresponding to a sufficiently ventilated fire within $20 \%$ error

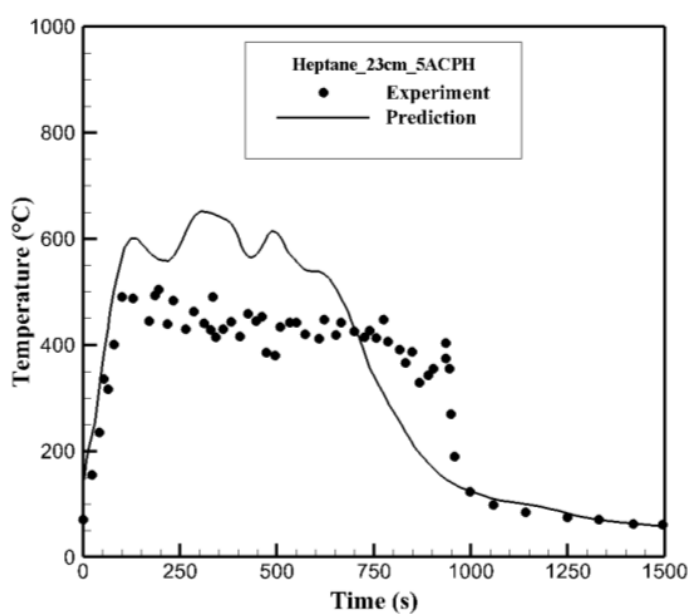

10b) Heptane pan of $23 \mathrm{~cm}$ at $5 \mathrm{ACPH}$ corresponding to a sufficiently ventilated fire within $20 \%$ error

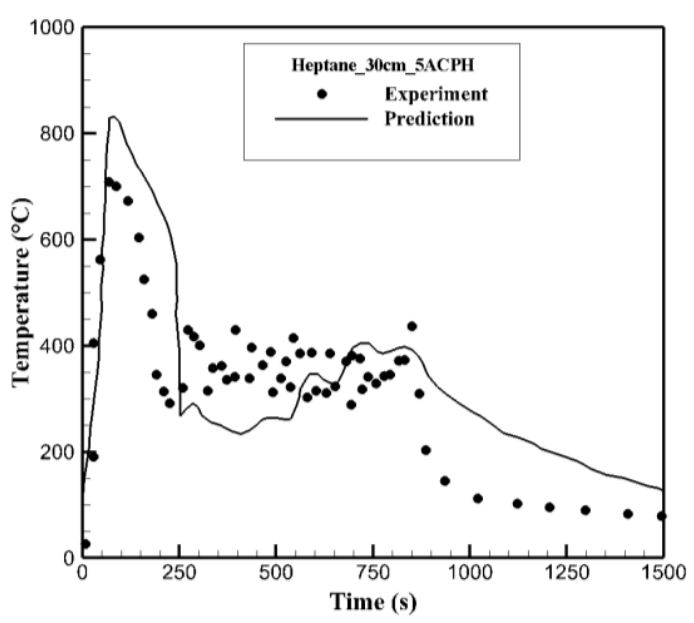

10c) Heptane pan of $30 \mathrm{~cm}$ at $5 \mathrm{ACPH}$ corresponding to an under-ventilated fire within $25 \%$ error 


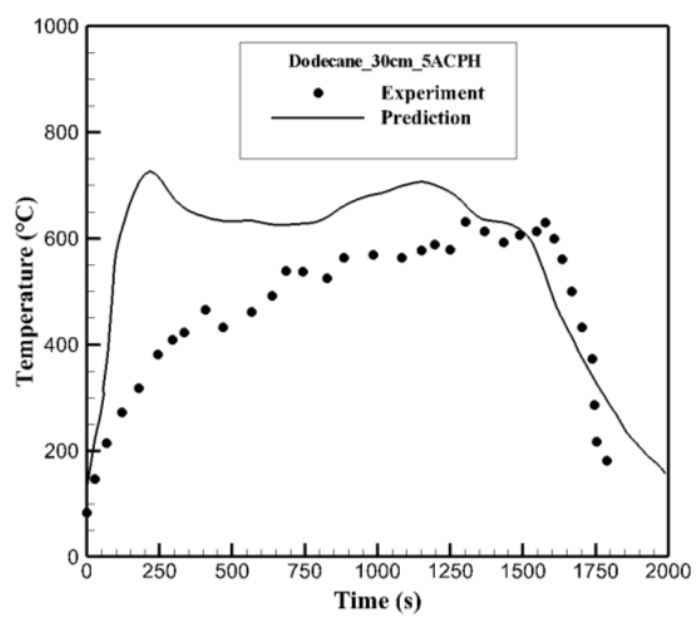

10d) Dodecane pan of $30 \mathrm{~cm}$ at $5 \mathrm{ACPH}$ corresponding to a sufficiently ventilated fire within $17 \%$ error

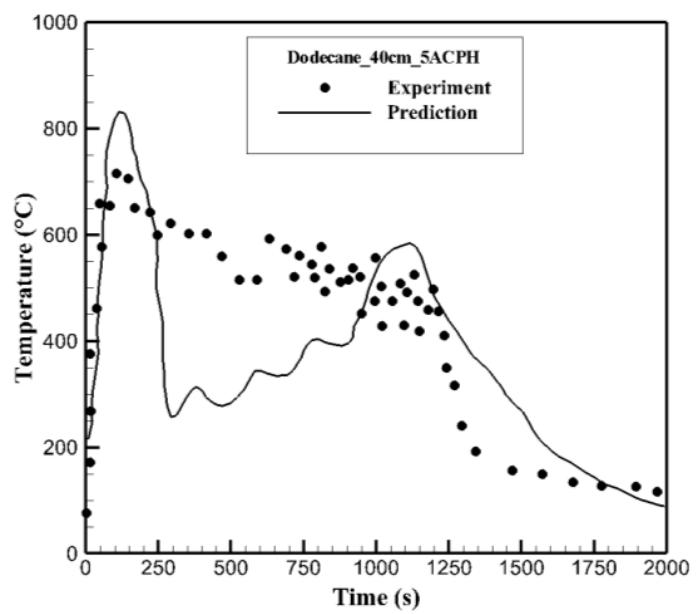

10e) Dodecane pan of $40 \mathrm{~cm}$ at $5 \mathrm{ACPH}$ corresponding to an under-ventilated fire within $50 \%$ error

Figure 10. Comparison between the calculated and the measured gas temperatures near the fire source with a discrepancy varying from $17 \%$ to $50 \%$ as a function of the ventilation condition or fuel type

\section{Conclusions}

In an engineering context, the calculated heat release rate (HRR), the temperature and the oxygen concentration agree well with the experimental results within $15 \%$ error, especially for the maximum values, in over-ventilated conditions. Quality of the agreement between the prediction and the experiment deteriorates in under-ventilated conditions. Oscillations of the HRR observed experimentally due to the ignition/extinction of the liquid fuel pan in underventilated conditions are apparently not well captured by the model with a discrepancy up to $50 \%$. This highlights the shortcoming of the use of a fast combustion model, irrespective to the chemical kinetic depending on the gas temperature. In medium-scale enclosure of $8 \mathrm{~m}^{3}$, ignition near the extraction duct can happen for heptane or dodecane pan with a diameter beyond 30 $\mathrm{cm}$, as long as the gas temperature is high enough for auto-ignition. In general terms, comparison between the prediction and the experiment is reasonably good for the occurrence of an ignition, although identification of the ignition time delay and location controlled by the fire scenario is within $15-30 \%$ error. In a full scale enclosure with an equivalent ratio higher than 1.5, when the fire has been established for sufficiently long with a temperature above $350^{\circ} \mathrm{C}$ near the ceiling, there is significant ignition risk of unburnt fuel gases in an exhaust 
system as long as any return of air from dilution duct occurs. The extinction/ignition criteria delivered in this work can be applied only in the case where the remaining flames as ghosting flame in the enclosure do not exist. With presence of a pilot flame as ghosting flame, ignition of unburnt volatiles near the exhaust system may occur more easily at temperature down to $350^{\circ} \mathrm{C}$. Any attempt to draw a general conclusion for all configurations is discouraged due to the uncontrollable fire dynamics which depends strongly on the distribution of the oxygen available in under-ventilated enclosure. The uncertainties in the ignition/extinction criteria are mainly due to our inability to measure detailed chemical species through bench-scale experiments, and other idealizations inherent in such empirical definition.

The work is continuing with the aim of improving the quality of the predicted chemical species concentration by using more complex chemistry reaction kinetics. Besides, effects of the internal liquid-phase circulation on the pyrolysis rate of liquid fuel should be modelled properly by taking into account the enhanced heat transfer within the liquid phase by e.g., lateral convection.

\section{References}

[1] Peatross, M.J. and Beyler, C.L. Ventilation effects on compartment fire characterization. In Fire Safety Science - Proceedings of the Fifth International Symposium, Vol.5, pp.403-414, 1997.

[2] Utiskul, Y. Theoretical and experimental study on full-developed compartment fires, Fire Engineering, University of Maryland, USA, 2006.

[3] Tewarson, A., Lee, J.L. and Pion, R.F. The influence of oxygen concentration on fuel parameters for fire modelling. Symp. (Int.) Combust., 18, 563-570, 1981.

[4] Orloff, L. and de Ris, J. Froude modelling of pool fires. $19^{\text {th }}$ International Symposium on Combustion. The Combustion Institute, pp.885-895, 1982.

[5] Hamins, A., Yang, J.C. and Kashiwagi, T. A global model for predicting the burning rates of liquid pool fires. Technical Report NISTIR-6381, NIST, 1999.

[6] Beaulieu, P., and Dembsey, N. Effect of oxygen on flame heat flux in horizontal and vertical orientations, Fire Safety J., 43, 410-428, 2007.

[7] B. Merci, K. and Van Maele. Numerical simulations of full-scale enclosure fires in a small compartment with natural roof ventilation. Fire Safety Journal, p. 495-511, 2008.

[8] J.Wahlqvist, P.V. Hees. Validation of FDS for large-scale well-confined mechanically ventilated fire scenarios with emphasis on predicting ventilation system behavior. Fire Safety Science, 62 Part B, pp. 102-114, 2013.

[9] Beji, T., Bonte F. and Merci, B. Numerical Simulations of a Mechanically-Ventilated MultiCompartment Fire. IAFSS Symposiums, 2014.

[10] Laurent Gay, Bertrand Sapa and Fatiha Nmira. MAGIC and Code_Saturne developments and simulations for mechanically ventilated compartment fires. Fire Safety Science, 62 Part B, pp. 161-173, 2013.

[11] F. Tang, L.H Hu, M. Delichatsios, K.H Lu and W. Zhu. Experimental study on flame height and temperature profile of buoyant window spill plume from an under-ventilated compartment fire, International Journal of Heat and Mass Transfer, p. 93-101, 2012

[12] H. Prétrel, W. le Saux and L. Audouin. Pressure variations induced by a pool fire in wellconfined and force-ventilated compartment. Fire Saf. J. 52 (2012) 11-24.

[13] S. Vilfayeau, N. Ren, Y. Wang and A. Trouvé. Numerical simulation of under-ventilated liquid-fueled compartment fires with flame extinction and thermally-driven fuel evaporation. Proceedings of the Combustion Institute 35 (2015) 2563-2571.

[14] Novozhilov, V. Computational fluid dynamics modelling of compartment fires. Prog. Energy Combust. Sci. 27, 611-666, 2001. 
[15] A. Nasr, S. Suard, H. El-Rabii, L. Gay and J.P. Garo. Fuel mass loss rate determination in a confined and mechanically ventilated compartment fire using a global approach, Combustion Science and Technology, 2011, pp.1342-1359.

[16] J. Lassus, E.Studer, J.P. and Garo, J.P. Vantelon et al. Influence of ventilation on ignition risk of unburnt gases in the extraction duct of underventilated compartment fire, Combustion Science and Technology, 2010, 182, pp.517-528.

[17] J. Lassus, L. Courty, E. Studer, J.P. Garo, P. Jourda and P. Aine. Estimation of species concentration during a fire in a reduced scale room, Journal of Fire Science, p.30-50, vol.34(1), 2016.

[18] Melguizo Gavilanes and Shepherd, J.E. Hot surface ignition and flow separation, $25^{\text {th }}$ ICDERS, Aug. 2-7, 2015, Leeds, UK.

[19] E.E. Zukoski, Fluid dynamics aspects of room fires, First International Symposium on Fire Safety Science, 1984, pp.1-30.

[20] McGrattan, K., Hostikka, S., Floyd, J., Baum, H. and Rehm, R. Fire Dynamics SimulatorTechnical Reference Guide; National Insitute of Standards and Technology: Washington, DC, USA, 2014; Number 1018.

[21] A. Murty Kanury, Introduction to Combustion Phenomena, New York: Gordon, ISBN 0677-02690-0, 1984.

[22] N. Djilali, I. Gartshore and M. Salcudean. Calculation of convective heat transfer in recirculating turbulent flow using various near-wall turbulence models, Numerical Heat Transfer 16, pp.189-212, 1989.

[23] Leung, K.M., Lindstedt, R.P. and Jones, W.P. A simplified reaction mechanism for soot formation in nonpremixed flames, Combustion and Flame, pp.289-305, 1991.

[24] Moss, J.B., Stewart, C.D. and Young, K.J. Modelling soot formation and burnout in a high temperature laminar diffusion flame burning under oxygen-enriched conditions, Combustion and Flame, 101, pp. 491-500, 1995.

[25] T. Beji, J. Zhang and Delichatsios M.A. Determination of soot formation rate from laminar smoke point measurements. Comb Sci and Tech, 180(5):927-940, 2008.

[26] B.F. Magnussen and I.S. Ertesvag. The eddy dissipation turbulence energy cascade model, Combustion Science and Technology, 159(1):213-235, 2000.

[27] V. Babrauskas, Ignition handbook, p.1116, USA, 2003. 